\title{
Preliminary signs of the initiation of deep convection by GNSS
}

\author{
H. Brenot ${ }^{1}$, J. Neméghaire ${ }^{2}$, L. Delobbe ${ }^{2}$, N. Clerbaux ${ }^{2}$, P. De Meutter ${ }^{3,2}$, A. Deckmyn ${ }^{2}$, A. Delcloo ${ }^{2}$, L. Frappez ${ }^{2}$, and \\ M. Van Roozendael ${ }^{1}$ \\ ${ }^{1}$ Belgian Institute for Space Aeronomie, Avenue Circulaire 31180 Brussels, Belgium \\ ${ }^{2}$ Royal Meteorological Institute of Belgium, Avenue Circulaire 31180 Brussels, Belgium \\ ${ }^{3}$ Astronomical Observatory, University of Gent, Krijgslaan 281 S9 9000 Gent, Belgium \\ Correspondence to: H. Brenot (brenot@oma.be)
}

Received: 4 July 2012 - Published in Atmos. Chem. Phys. Discuss.: 14 August 2012

Revised: 16 April 2013 - Accepted: 23 April 2013 - Published: 3 June 2013

\begin{abstract}
This study reports on the exploitation of GNSS (Global Navigation Satellite System) and a new potential application for weather forecasts and nowcasting. We focus on GPS observations (post-processing with a time resolution of 5 and $15 \mathrm{~min}$ and fast calculations with a time resolution of $5 \mathrm{~min}$ ) and try to establish typical configurations of the water vapour field which characterise convective systems and particularly which supply precursors of their initiation are associated with deep convection. We show the critical role of GNSS horizontal gradients of the water vapour content to detect small scale structures of the troposphere (i. e. convective cells), and then we present our strategy to obtain typical water vapour configurations by GNSS called " $\mathrm{H}_{2} \mathrm{O}$ alert". These alerts are based on a dry/wet contrast taking place during a 30 min time window before the initiation of a convective system. GNSS observations have been assessed for the rainfall event of 28-29 June 2005 using data from the Belgian dense network (baseline from 5 to $30 \mathrm{~km}$ ). To validate our GNSS $\mathrm{H}_{2} \mathrm{O}$ alerts, we use the detection of precipitation by $\mathrm{C}$-band weather radar and thermal infrared radiance (cloud top temperature) of the 10.8-micrometers channel [Ch09] of SEVIRI instrument on Meteosat Second Generation. Using post-processed measurements, our $\mathrm{H}_{2} \mathrm{O}$ alerts obtain a score of about $80 \%$. Final and ultra-rapid IGS (International GNSS Service) orbits have been tested and show equivalent results. Fast calculations (less than $10 \mathrm{~min}$ ) have been processed for 29 June 2005 with a time resolution of $5 \mathrm{~min}$. The mean bias (and standard deviation) between fast and reference postprocessed ZTD (zenith total delay) and gradients are, respectively, $0.002( \pm 0.008) \mathrm{m}$ and $0.001( \pm 0.004) \mathrm{m}$. The score obtained for the $\mathrm{H}_{2} \mathrm{O}$ alerts generated by fast calculations is $65 \%$.
\end{abstract}

\section{Introduction}

For $20 \mathrm{yr}$, data from ground-based GNSS (Global Navigation Satellite System) receivers have been used to accurately measure the path delay of the neutral atmosphere, which highly depends on the water vapour content above the associated antenna (Bevis et al., 1992). The most used GNSS meteorological observation is generally called zenith path delay or zenith total delay (ZTD) of the neutral atmosphere. This observation (strongly related to the water vapour content variation), which describes the mean delay above a GNSS site, can also be associated with another observation of the neutral atmosphere: the horizontal delay gradient $\vec{G}$ (north-south and east-west components) (Chen and Herring, 1997). The objective of this work is to show the value of GNSS observations for weather forecasts, especially for nowcasting. We will focus on GPS observations of ZTD and $\vec{G}$ (postprocessing with a time resolution of $15 \mathrm{~min}$ ) and try to answer the following question:

Can the detection of the water vapour content by GNSS allow us to establish typical configurations of this field which characterise convective systems and particularly which supply precursors of their initiation are associated with deep convection?

After a presentation of the rainfall event of the 28-29 June 2005 (case study of this paper), we will show the value of horizontal GNSS delay gradients for detecting small scale structures in the troposphere (Davis et al., 1993; Chen and Herring, 1997; Gradinarsky, 2002). An improvement of the humidity field observed by GNSS considering gradients will be shown. Then, using a new detection of humidity structures, we will present our strategy to obtain a GNSS indicator 

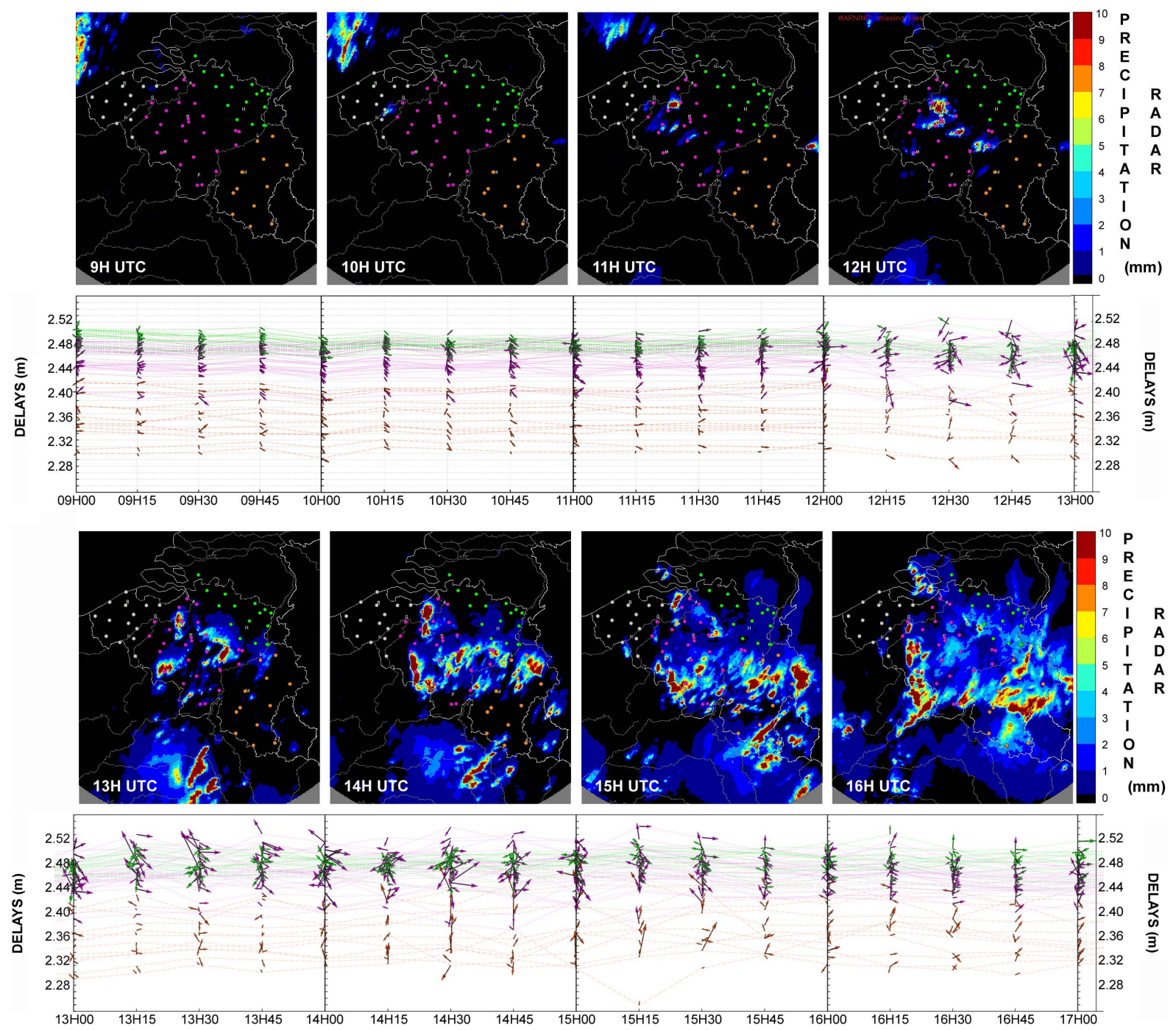

Figure 1. Sequence of hourly precipitation detected by radar from 09:00 to 24:00 UTC (29 June 2005). GNSS stations are plotted on this map with 4 different colours dedicated to 4 geographical regions. Time series of GNSS horizontal gradients $\vec{G}$ are shown below using the same 4 dedicated colours.

of the initiation of deep convection. The initiation of a deep convection system is a complex and unique phenomenon. To validate our typical configurations of the humidity field (based on a dry/wet contrast obtained by GNSS) called " $\mathrm{H}_{2} \mathrm{O}$ alert", we will use two other indicators of deep convection obtained by meteorological radar and SEVIRI instruments on Meteosat Second Generation. These two techniques each give an independent, good indication of the deep convection. We will present these two indicators (detection of precipitation by C-band weather radar and thermal infrared radiance of the 10.8-micrometers channel [Ch09] by SEVIRI instrument) and show the statistical results and the validation of our $\mathrm{H}_{2} \mathrm{O}$ alerts for the 28-29 June 2005 rainfall event. Two types of calculations are considered: a reference post-processing (with different final and ultra-rapid IGS orbits) and a fast post-processing. Then we will highlight some conditions and perspectives in order to show how our GNSS $\mathrm{H}_{2} \mathrm{O}$ alerts can be used in an operational nowcasting system.

\section{Rainfall event of 28-29 June 2005}

From the afternoon of 28 to the evening of 29 June 2005, a continuous period of precipitation was observed over the main part of Belgium (see Fig. 1). The meteorological situation for this period was the following.

At 00:00 UTC on 29 June 2005, the isobaric analysis (at $500 \mathrm{hPa}$ and $850 \mathrm{hPa}$ ) indicated that a warm and humid air mass was advected from the north of France to Belgium in the lower tropospheric layers. This advection was characterised by a wet-bulb, pseudo-equivalent potential 


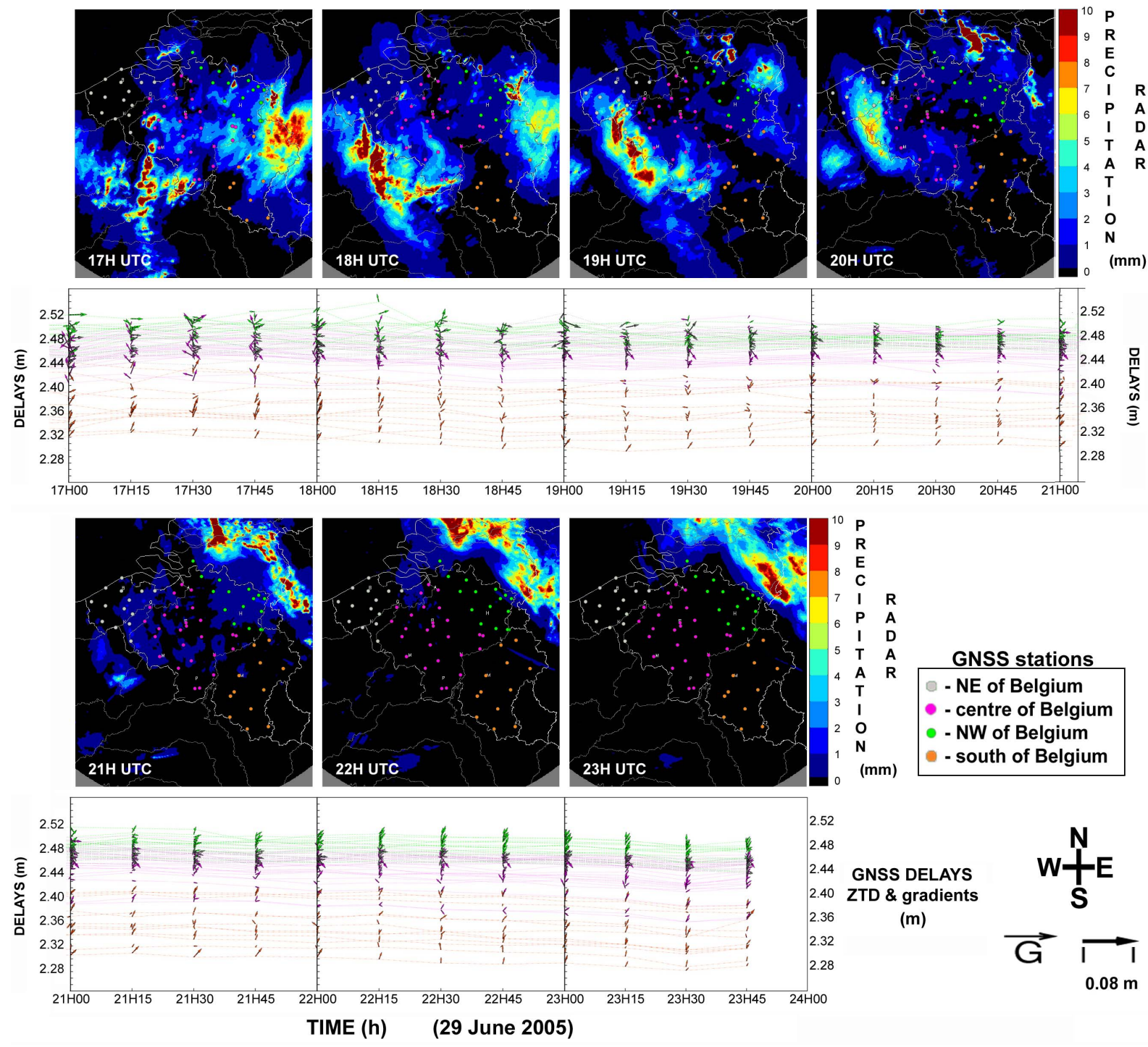

Figure 1. Continued.

temperature maximum field associated with a ridge of high pressure over Belgium (see Fig. 2.9 and 2.12 of Neméghaire and Brenot, 2010, available on http://h2o.oma.be/RMIB num59_oct2010.pdf). The surface analysis indicated a complex low pressure area over Belgium and the north of France. It confirmed the advection of mild and humid air mass in the lower tropospheric levels down to the surface. At the surface, this air mass was characterised by high dew point temperatures which increased rather homogeneously up to about $16^{\circ}$ to $18^{\circ} \mathrm{C}$ over these areas. The dew point depression (difference between temperature and dew point temperature at the surface) was small and did not exceed $3^{\circ} \mathrm{C}$ (see Fig. 2.10 of Neméghaire and Brenot, 2010). The analysis (at 00:00 UTC) of the Convective Available Potential Energy (CAPE) and the Convective Inhibition (CIN) fields from the European Centre for Medium-Range Weather Forecasts (ECMWF with a $30 \mathrm{~km}$ resolution) showed CAPE values mostly between 1000 and $2000 \mathrm{~J} \mathrm{~kg}^{-1}$ over the north of France while CIN values had locally negative values of about $500 \mathrm{~J} \mathrm{~kg}^{-1}$. Note that a CAPE amplitude 2 or 3 times larger than the associated CIN one indicates a potential instability of the air mass (in our case at 00:00 UTC over the north of France). Nevertheless, on 29 June at 00:00 UTC, the air remained more stable over Belgium with small CAPE values.

At noon on 29 June, the upper-air isobaric analysis shown in Fig. $2 b$ indicated that the ridge of high pressure gradually gave way to an upper cold air advection associated with a low pressure $(L)$ moving from the northwest of France and the Channel towards Belgium. In the lower troposphere, a "tongue" of rather warm and humid air still remained with wet-bulb, pseudo-equivalent potential temperatures of about $16^{\circ} \mathrm{C}$ at $850 \mathrm{hPa}$ (see Fig. 2a). We observed a complex low 


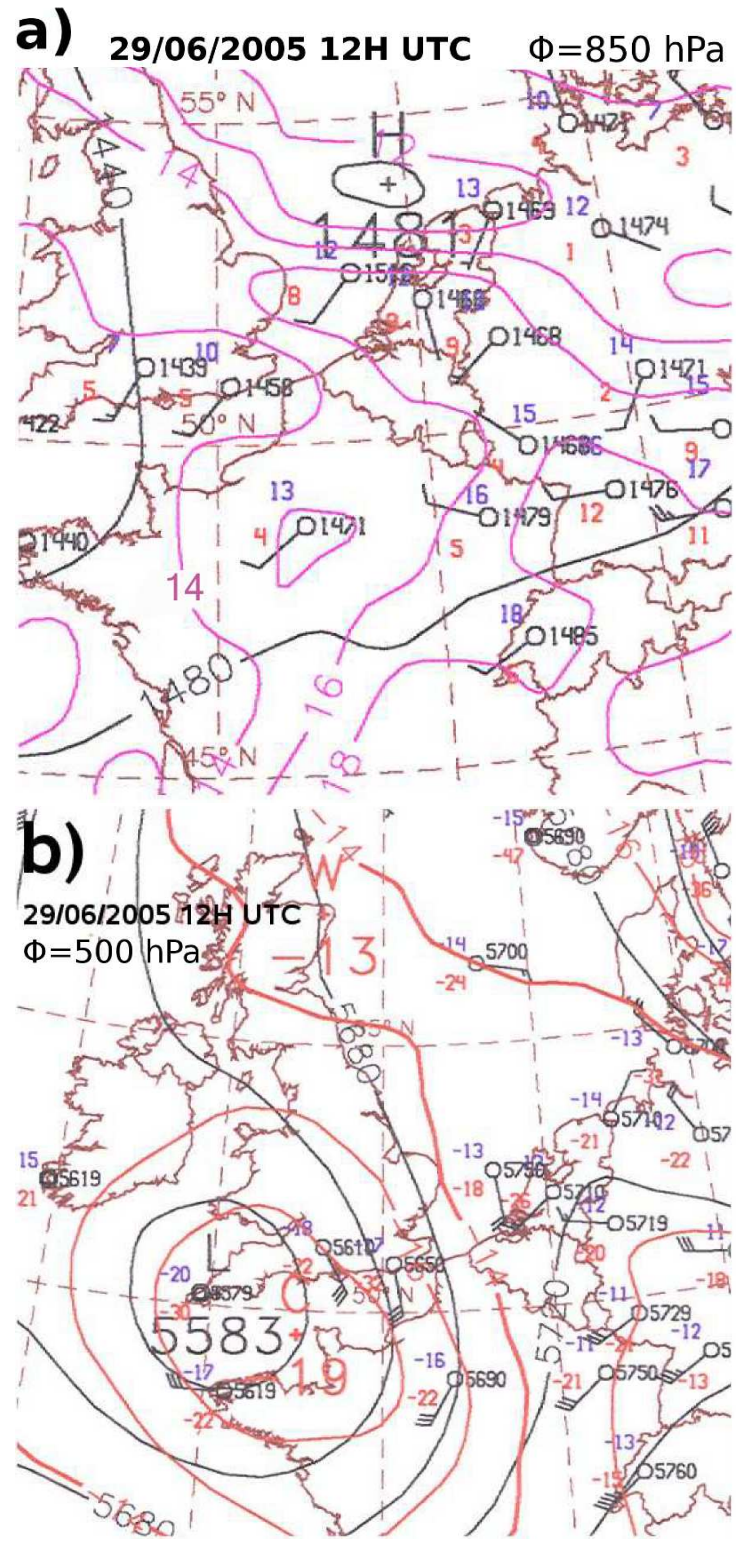

Figure 2. Isobaric analysis (a) at $850 \mathrm{hPa}$, (b) at $500 \mathrm{hPa}$ over Western Europe derived from ECMWF background and radiosondes observations (29 June 2005). The black contours are the geopotential heights. The magenta contours represent the wet-bulb, pseudoequivalent potential temperature. The observed radiosonde data are indicated on the chart (temperatures in blue, dew point temperatures in red, wind flags and geopotential heights in black).

pressure area characterised by several centres which tended to deepen slightly over Belgium during the afternoon. The warm and humid air mass which had been advected over Belgium the previous night was at this time stagnating. At the surface, this air mass was traced by the analysis of the dew point temperatures (between 16 and $18^{\circ} \mathrm{C}$ ) and a larger dew point depression influenced by the diurnal warming. These higher surface temperatures associated with a more inhomo- geneous dew point distribution indicated a significant convective mixing at least close to the surface. Using the Belgian synoptic network (pressure and surface winds), lines of convergences have been identified during this event. These were associated with a low pressure trough, as shown at 12:00 UTC (29 June 2010) in Fig. 3. For this period, using ECMWF model at 12:00 h (initialised at 00:00 h), the CAPE field (see Fig. 4a) shows significant values (from 1000 to $1600 \mathrm{~J} \mathrm{~kg}^{-1}$ ). CIN amplitudes from -50 to $-150 \mathrm{~J} \mathrm{~kg}^{-1}$ have been estimated (see Fig. 4b). They indicated large (static) instability in these areas which remained significant in the afternoon up to at least 18:00 UTC and moved slowly northeastwards. The CAPE and CIN fields computed with our regional limited area model (ALADIN model with a $7 \mathrm{~km}$ resolution in 2005; see www.cnrm.meteo.fr/aladin for more details) confirmed the instability detected by ECMWF for the same period, with higher CAPE and lower CIN values obtained over Belgium (see the analysis at 12:00 UTC in Fig. 4c, d).

The advection identified by the upper-air and surface analyses (Figs. 2 and 3 ) has been confirmed by the radiosonde at Uccle (Brussels, Belgium); see the skew $(T-\ln P)$ diagram in Fig. 5 at 12:00 UTC (29 June 2005) which shows warm and rather moist air in the lower tropospheric layers (with high dew point temperatures) and drier air above $700 \mathrm{hPa}$ (with low dew points). The synoptic station of Uccle was in the area of the convergence line shown in Fig. 3, where warm and moist lower air were converging. An increase of the wind, which was backing up to the jet stream level (up to 60 knots between 250 to $300 \mathrm{hPa}$; see the windbarbs presented at the $P$ level every 10 observations in Fig. 5), was measured by the radiosonde with a CAPE of $868 \mathrm{~J} \mathrm{~kg}^{-1}$ and a CIN of $-1.05 \mathrm{~J} \mathrm{~kg}^{-1}$ (at 12:00 UTC). Note that for this location (Brussels), a CAPE of $1200 \mathrm{~J} \mathrm{~kg}^{-1}$ and a CIN of $-37 \mathrm{~J} \mathrm{~kg}^{-1}$ were obtained from ECMWF model, and a CAPE of $1671 \mathrm{~J} \mathrm{~kg}^{-1}$ and a CIN of $0 \mathrm{~J} \mathrm{~kg}^{-1}$ from ALADIN model. The signature of warm and moist air in the lower tropospheric area was characterised by high wet-bulb, pseudoequivalent potential temperatures. At 12:00 UTC, The dry air above $700 \mathrm{hPa}$ indicated a decreasing wet-bulb, pseudoequivalent potential temperature with altitude that can contribute to a stronger convective instability.

To summarise, between 10:00 and 16:00 UTC on 29 June, the surface analysis and the CAPE/CIN fields from the radiosonde at 12:00 (Uccle) and models (ALADIN and ECMWF) indicated a convective episode over Belgium. In the neighbourhood of identified lines of convergence, several clusters of convective cells were developing within a short time (see hourly radar precipitation in Fig. 1). Several convective cells were observed by the SEVIRI instrument on Meteosat (infrared channel). Thick cumuliform clouds with high vertical extensions and cold tops were associated with these cells (see Fig. 6). During the morning of 29 June, clusters of convective cells were distinct with a spatial extension of about $10 \mathrm{~km}$. But finally clusters were stretched by the 


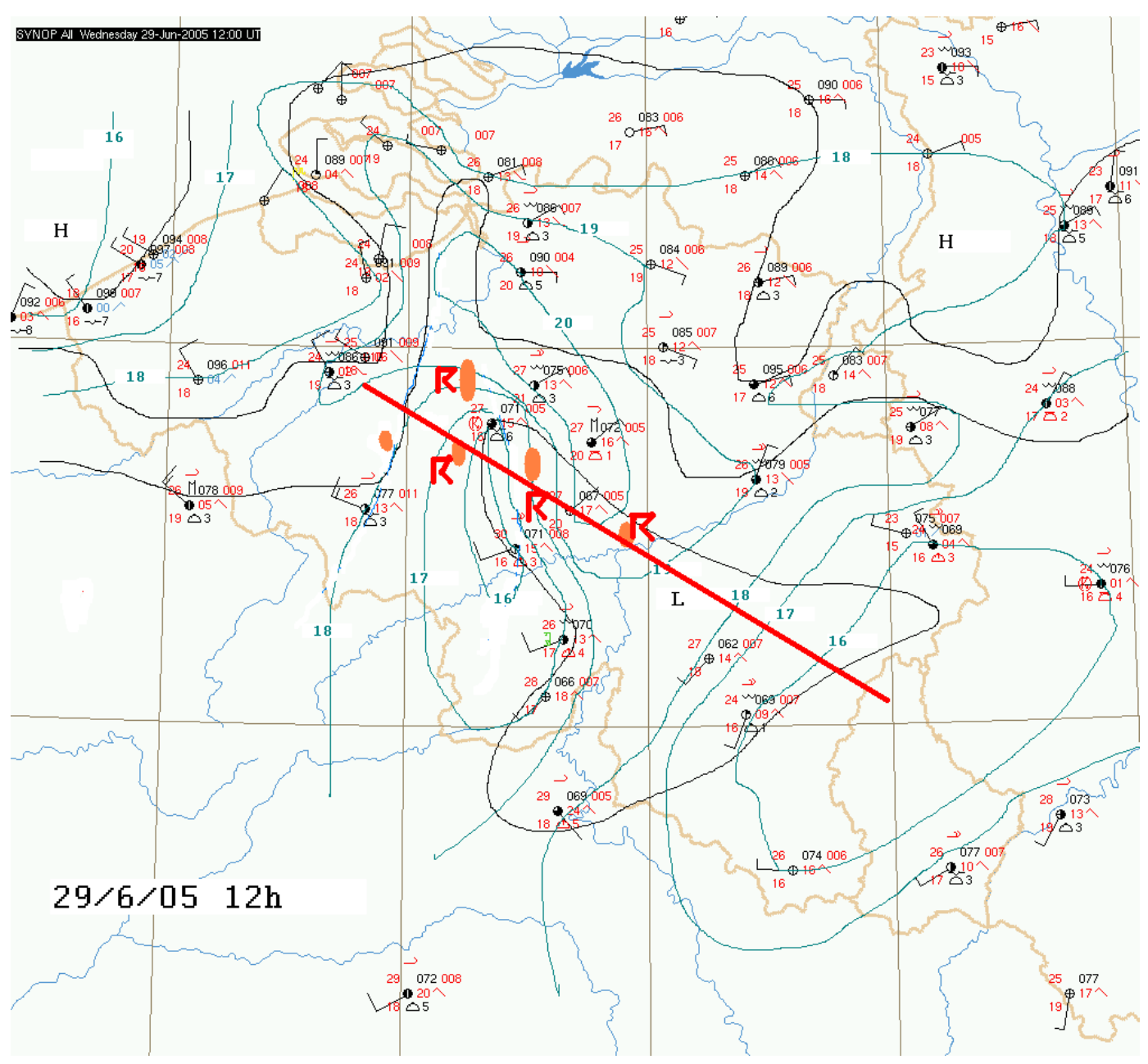

Figure 3. Meso-scale surface analysis based only on observations. Plot of the major line of convergence is shown in red, radar precipitation in orange, thunderstorms detected by SAFIR in R-shape red symbols, contours of the dew point temperature in green, and contours of the mean sea level pressure in black. The synoptic observations are indicated on the chart (temperature and dew point in red, wind flag and the mean sea level pressure in black).

diffluent air flow in the mid-troposphere, as shown on the isobaric analysis at $500 \mathrm{hPa}$ (see Fig. 2b). This diffluent air flow pattern was associated with the low pressure centred over the Channel. A significant variation of the wind speed and its direction following the altitude (indicated by the vertical shear of the wind) affected and increased the vertical development and asymmetric shape of the clusters. The SEVIRI composite visible image (Fig. 7) showed the development of several thick cloud cells, with a signature of cloud stretching and vertical development (indicated by the plume in light blue colour). The shapes of these cloud cells were strongly related to the wind shear in the troposphere along the convergence line (see Fig. 3). The intensification of convective activity induced a complex meso-scale convective system. Gradually this system covered the major part of Belgium, resulting in heavy precipitation (up to about $100 \mathrm{~mm} \mathrm{day}^{-1}$ ) and thunderstorms. In the north-west of the country, the convective activ- ity was limited (see Fig. 1). Neméghaire and Brenot (2010) gave a more precise description of this meteorological event.

The prediction of rainfall from this complex convective system, using ECMWF and the regional forecast from ALADIN, using data from the Belgian synoptic network and using the near real-time meteorological observations (radar, SAFIR, Meteosat), was not so helpful at this time for the nowcasting. For this reason, the aim of our study is to find a new near real-time observation that could be used by forecasters as an indicator of preliminary signs of the initiation of deep convection. In the following section, we will briefly present the GNSS meteorological technique and the two types of observations which can be operationally used to detect water vapour structure of the troposphere. 


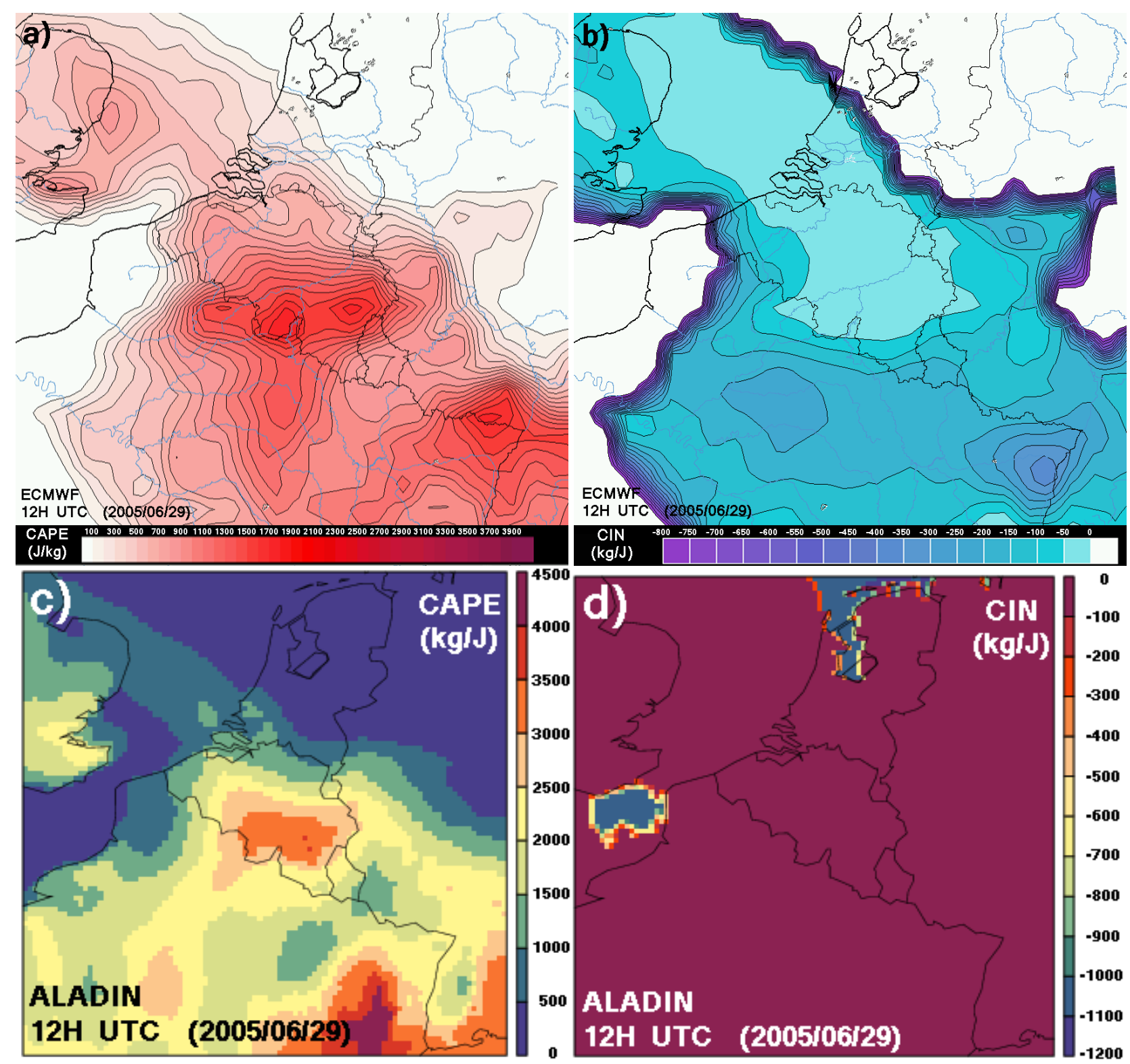

Figure 4. Estimations of (a) CAPE and (b) CIN from ECMWF model at 12:00 UTC (29 June 2005). ECMWF model started at 00:00 UTC (29 June 2005). Estimations of (c) CAPE and (d) CIN from the analysis of ALADIN regional model at 12:00 UTC (29 June 2005).

\section{Water vapour field using GNSS geodetic software}

The Global Navigation Satellite System (GNSS) technique can actually use a constellation of about 30 satellites (GPS, GLONASS, and GALILEO). In this study, only GPS satellites have been considered. During the case study of this paper, 68 Belgian ground-based GNSS receivers have recorded the GNSS signals emitted by 24 GPS satellites. To obtain meteorological observations, we have used the records of two phases (frequencies $L_{1}$ and $L_{2}$ ). Initially, geodetic software have been developed to calculate precisely the positions of stations (by least-square adjustment of phase delay records). Because the water vapour content of the neutral atmosphere (mainly the troposphere) can consequently decrease the speed of the propagation of the GNSS radio signal, the meteorological activity can have an impact on the precision of these positioning solutions. For this reason, positions and water vapour contents can simultaneously be adjusted (see Sect. 3.1).

The use of ground pressure and temperature can allow a conversion of the GNSS tropospheric path delay into a water vapour content. This study will only focus on delay observations because these, being more precise, are the initial GNSS measurements. Because GNSS technique measures data from different satellites, Sect. 3.2 shows two types of GNSS tropospheric observations. The first one, described as 


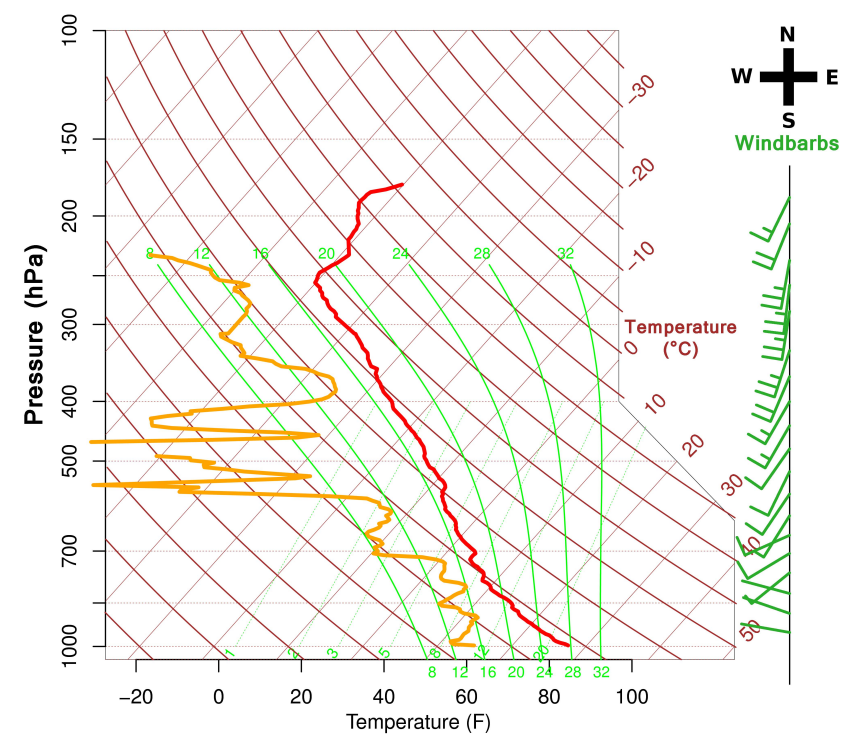

Figure 5. Skew $(T-\ln P)$ diagram of the radiosonde measurements at Uccle station on 29 June 2005 at 12:00 UTC (Brussels). The state curve is in red, the dew point curve in yellow, the moist adiabats in green, and the dry adiabats in brown. The windbarbs are presented on the right in dark green.

isotropic, corresponds to the estimation of the delay of propagation of GNSS signal at the zenith of a station. The second one, described as anisotropic, corresponds to the estimation of the horizontal gradient of the path delay (which can be used to estimate the distribution of the water vapour content around a station).

Finally, Sect. 3.3 presents how a combination of zenith delays and horizontal delay gradients measurements can improve the time and space resolution of the 2-D field of delay observed by GNSS (which can be used to estimate the 2-D field of water vapour content).

\subsection{Precise positions and neutral atmosphere measurements}

Since 1992 (Bevis et al., 1992), GNSS networks have been used to characterise horizontal water vapour content fields of the troposphere. In this study, we have measured zenith total delay of the neutral atmosphere (so called tropospheric ZTD) and horizontal delay gradients with the GAMIT geodetic software (version 10.4, Herring et al., 2010). GAMIT software uses double differences of observations to avoid the clock parameter in the adjustment. Note that other geodetic software (e. g. GIPSY) do not use the double differences technique, resolving the clock parameter in the adjustment.

To measure such atmospheric observations, a precise knowledge of the positions of all GNSS stations is required. Initially, ZTD and horizontal delay gradients have been introduced in GNSS calculations to improve the positioning solution (Bar-Sever and Kroger, 1998). The least-square ad- justment of ZTD and gradients by GAMIT software, in addition to positions, increases the precision of positions. In a primary GAMIT calculation we have estimated precise coordinates for all the local stations (about 70) of the Belgian dense network (Fig. 8). Daily sessions of calculations for a period of 5 days of GNSS phase records have been processed (ZTD estimated every $2 \mathrm{~h}$, and gradients every $6 \mathrm{~h}$ ). Unconstrained daily positions (free of external constrains in the adjustment) have been considered and converted into a final global solution. To obtain the final positions in the ITRF2000 (International Terrestrial Reference Frame) (see Altamimi et al., 2002), the positions of only 10 reference European stations (called fiducial stations) have been constrained using a Kalman filter (called GLOBK, see Herring et al., 1990). To proceed the adjustment of the data (recorded in direction of satellite), the use of a mapping function is required to model the troposphere and the propagation of signal at low elevation (or high zenith angle). The precision of our positions obtained with Niell mapping function (1996) is millimetric, which is sufficient for our meteorological application.

Using the precise positions of stations, a secondary GAMIT calculation has been processed to obtain meteorological observations. Zenith tropospheric delays and horizontal tropospheric gradients (two components, north-south and east-west) have been calculated considering reference zenith and gradient variations of $0.02 \mathrm{~m} \mathrm{~h}^{-1 / 2}$ (Herring et al., 2010, Sects. 2.3, 7.3 and 7.4). To un-correlate tropospheric measurements and vertical position estimations in the double differences process, baselines (or distance between two stations) greater than $2000 \mathrm{~km}$ have been considered in calculations (see Tregoning et al., 1998). For more details see Brenot et al. (2006). Finally, ZTD measurements have been produced using a sliding window strategy with 6 sessions of $12 \mathrm{~h}$ of data shifted by $4 \mathrm{~h}$ for daily measurements (see Herring et al., 2010; Chapter 1, Brenot, 2006). A cut-off elevation angle of $10^{\circ}$ has been applied. ZTD and gradient observations have been assessed with a time resolution of $15 \mathrm{~min}$.

\subsection{Isotropic and anisotropic contributions of the water vapour field using GNSS}

Ground-based GNSS receivers record the evolution of the phases of the dual frequency GNSS signal (phases $L_{1}=1.57542 \mathrm{GHz} ; L_{2}=1.22760 \mathrm{GHz}$ for the GPS) emitted by all the visible satellites (from 5 to 10 satellites, depending on time of day and the position of the station). The absolute slant phase delay in direction of a satellite cannot directly be measured. The integer number of phase cycle (called the ambiguity) needs to be fixed (Bock et al., 1985, 1986; Dong and Bock, 1989; Leick, 1989) to know precisely the slant delays in direction of a satellite. After the ambiguities of the signal in directions of GNSS satellites have been fixed, GAMIT software proceeds to a second calculation to estimate ZTD and gradients. The ZTD are obtained considering a priori zenith hydrostatic delays (ZHD) combined with zenith wet 


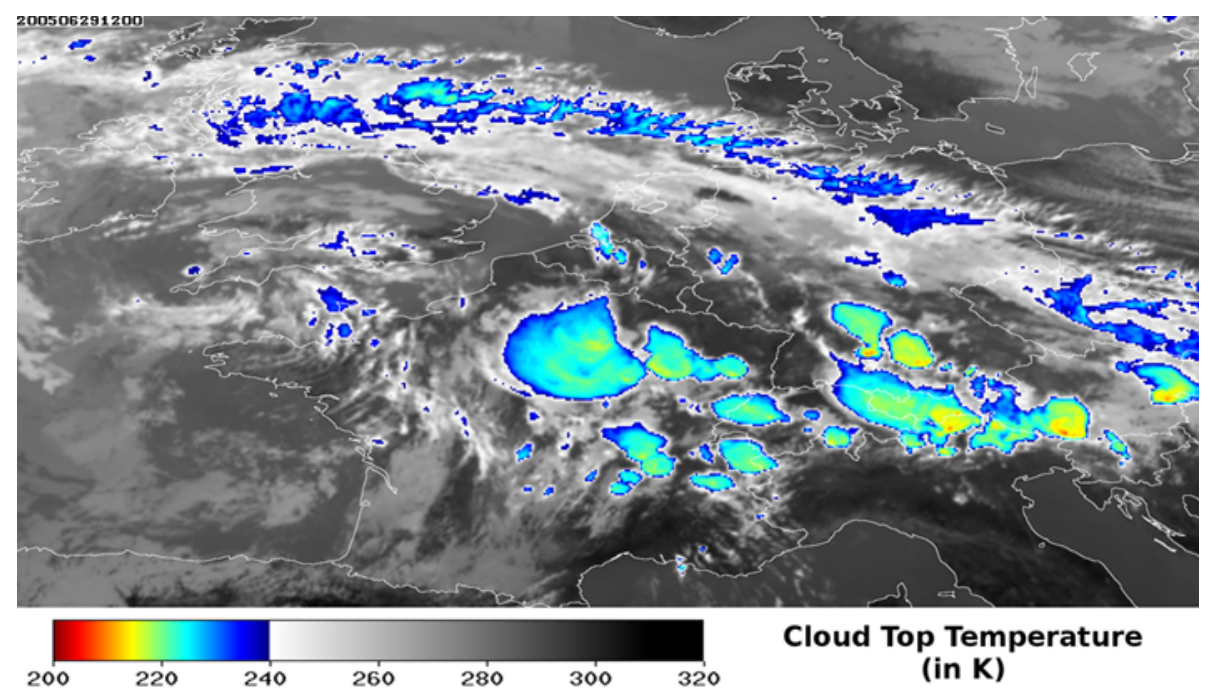

Figure 6. SEVIRI images of the cloud top temperature of the IR channel (29 June 2005 at 12:00 UTC).

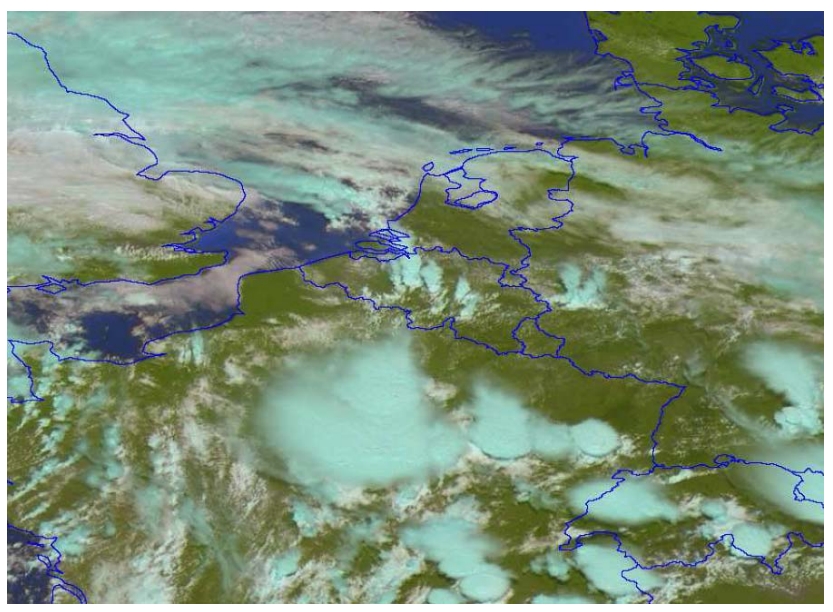

Figure 7. Natural colour composite image of SEVIRI visible channels at $0.6 \mathrm{~m}, 0.8 \mathrm{~m}$ and $1.6 \mathrm{~m}$ (29 June 2005 at 12:00 UTC). For the cloud, a blue colour indicates that the top of the cloud is composed of ice crystals while the white indicate liquid water droplets.

delays (ZWD) adjustments established from the phase residuals between model and records in directions of satellites (Tregoning and Herring, 2006); see Brenot et al. (2006) for a description of ZHD and ZWD. Simultaneously the GNSS delay gradients are adjusted considering the phase residuals and a correction of the mapping function (Niell, 1996) with an azimuthal dependency (Chen and Herring, 1997; Herring et al., 2010, Sect. 7.4). Two components (north-south and eastwest) are adjusted (for more details see Davis et al., 1993; Gradinarsky, 2002). Note that the delays of GNSS signals are induced by the ionosphere and the neutral atmosphere. The ionosphere is dispersive for GNSS signals. The use of double difference of a linear combination of $L_{1}$ and $L_{2}$, so-called ionosphere-free combination (see Spilker, 1980; King et al.,

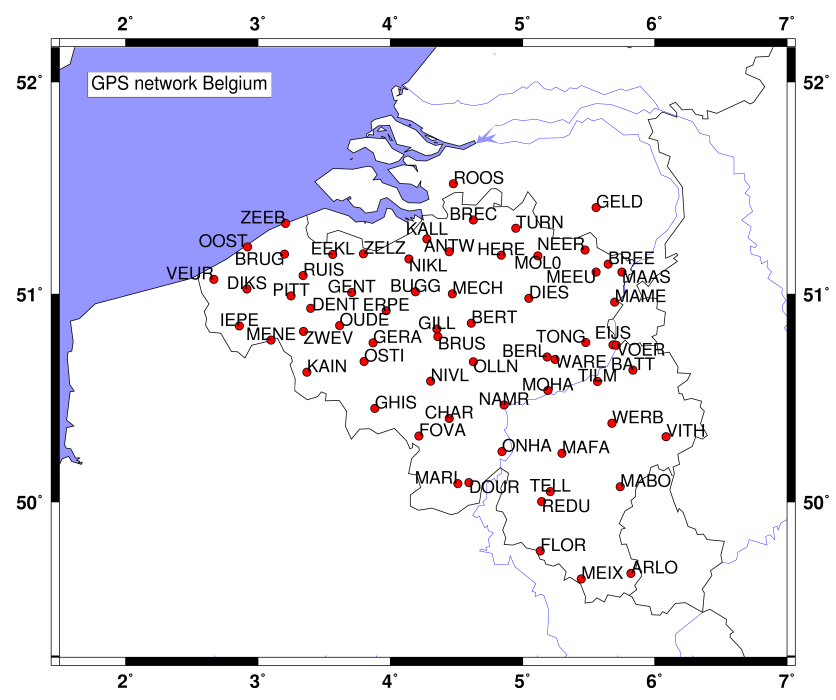

Figure 8. Belgian dense network of GPS stations.

1985; Brunner and Gu, 1991; Brenot and Warnant, 2008) allows for focusing only on the delay induced by the neutral atmosphere.

Considering all the visible satellites, the ZTD corresponds to the mean tropospheric delay above a station. This observation can be described as isotropic because, using a mapping function (with an azimuthal independency), the main contribution of the slant tropospheric delay in direction of a visible satellite (1st order of amplitude) can be obtained. For a station located at sea level, the ZHD (induced by all the density of the dry and wet troposphere) is estimated to be about $2.2 \mathrm{~m}$. The variation of the ZWD (induced by water vapour) can be from $0.05 \mathrm{~m}$ up to $0.5 \mathrm{~m}$. The projection of ZTD at $10^{\circ}$ 

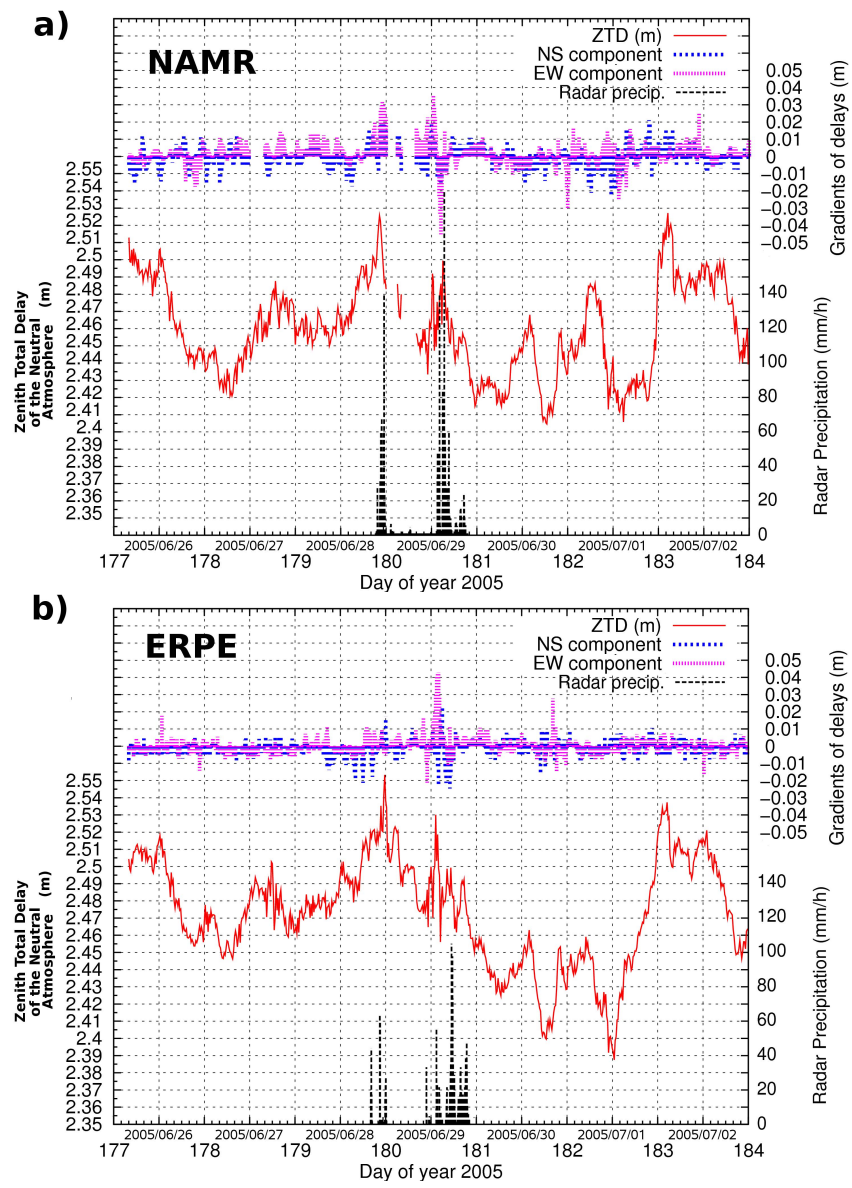

Figure 9. Time series of GNSS zenith total delays of the neutral atmosphere (ZTD), GNSS horizontal delay gradients (NS and EW components), and radar precipitation for (a) NAMR station (missing data the morning of 29 June) and (b) ERPE station, from 25 June 2005 to 3 July 2005.

of elevation can be about $14 \mathrm{~m}$ (with a contribution of water vapour to the path delay from about $0.3 \mathrm{~m}$ to $3 \mathrm{~m}$ ).

The second (anisotropic) contribution of the slant tropospheric delay in direction of a satellite can be obtained using the delay gradients. This contribution can be up to about $0.2 \mathrm{~m}$ at $10^{\circ}$ of elevation (2nd order of amplitude). Contributions of GNSS gradients to slant delays (Chen and Herring, 1997) can be mapped in the zenith direction (Niell, 1996); millimetric values can be observed and will be used in this study.

GNSS gradients, described by two components NS and EW, estimate the local anisotropic contribution of slant path delay around a GNSS antenna (which is related to the local water vapour anisotropy; see Gradinarsky, 2002); GAMIT normalises this contribution at $10^{\circ}$ of elevation (centimetric values of NS and EW components; up to a few tens of centimetres). Note that $6 \mathrm{~mm}$ of delays is equivalent to $1 \mathrm{~kg} \mathrm{~m}^{-2}$, $\sim 1 \mathrm{~mm}$ of precipitable water.

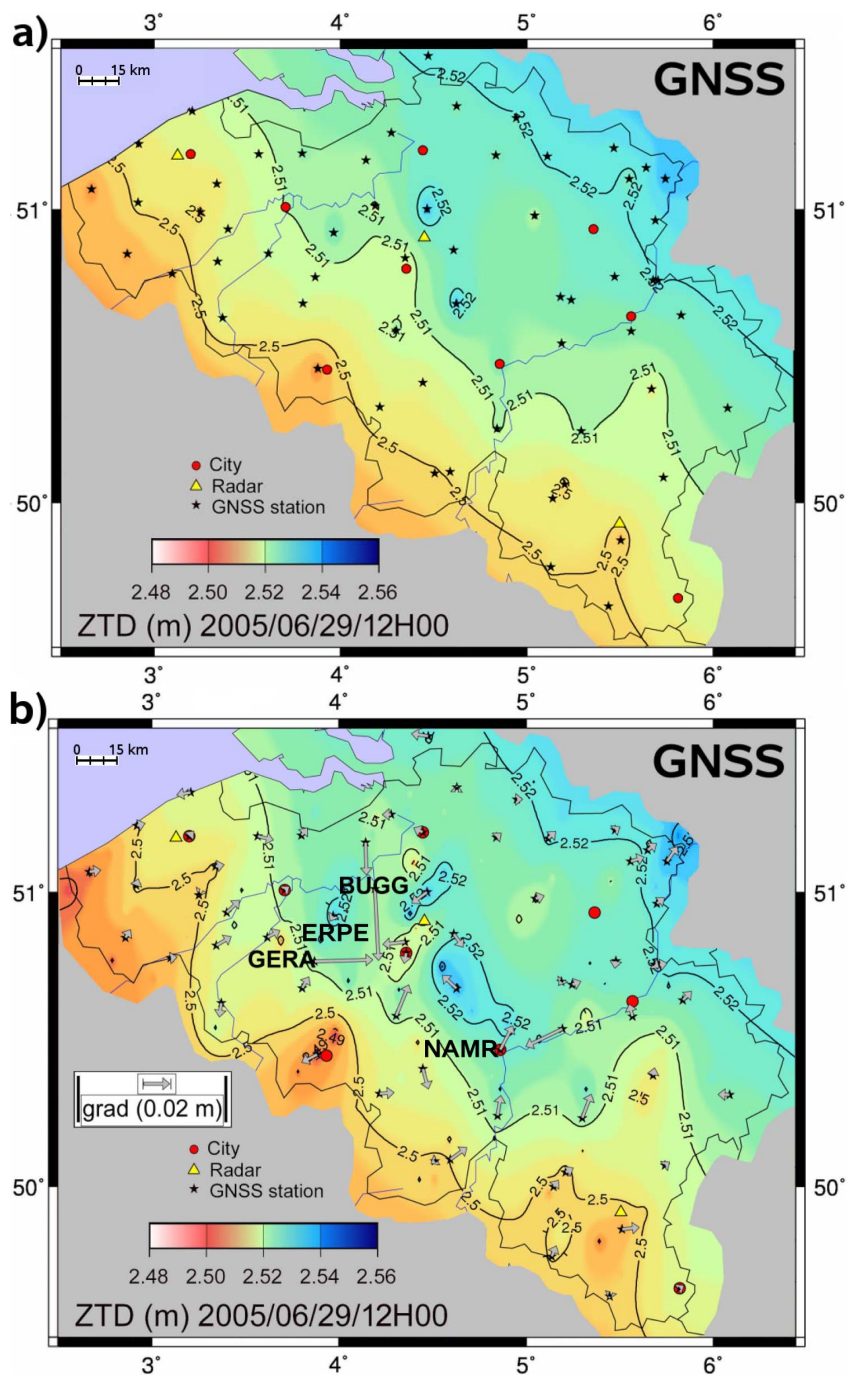

Figure 10. (a) Imaging of the 2-D field of ZTD with a classic interpolation (stations are plotted by black stars); (b) improvement of this field by GNSS gradients. These gradients $\vec{G}$ are plotted by grey arrows at each GNSS site. BUGG, ERPE, GERA and NAMR stations are plotted. Locations of 9 major Belgium cities (red circles) and meteorological radars (yellow triangles) are also plotted on these 2-D maps.

Contributions of GNSS gradients to slant delays (Chen and Herring, 1997) can be mapped in the zenith direction (Niell, 1996); millimetric values can be observed (up to a few centimetres) and will be used in this study. Figure 9 shows time series of ZTD and (NS, EW) gradient components for two Belgian GNSS stations (ERPE and NAMR), as well as the time series of radar precipitation. We can see that strong precipitation was observed during the 28-29 June 2005 event. High variations of the ZTD field (increase or decrease of $8 \mathrm{~mm}$ ) and the improvement of its spatial resolution by GNSS gradients is often correlated (score of $63 \%$ ) with high precipitation (more than $10 \mathrm{~mm} \mathrm{~h}^{-1}$; see Fig. 1). Nevertheless, we 
a)

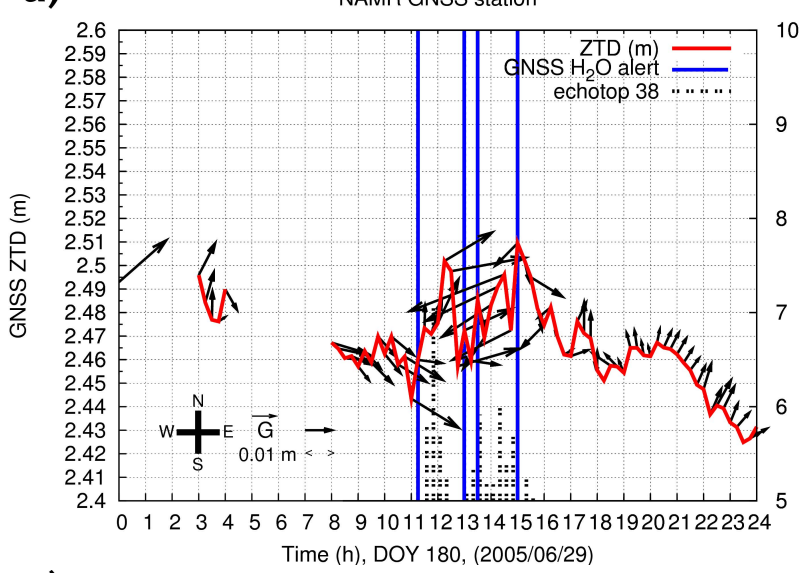

C)

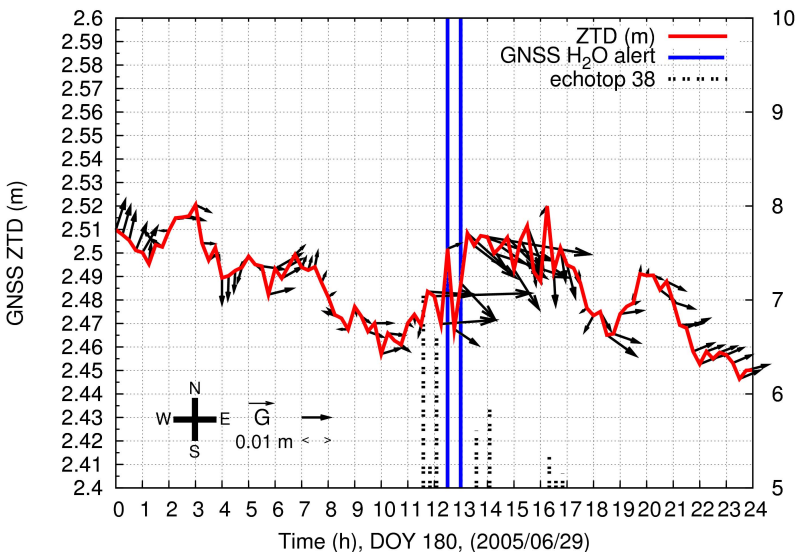

b)
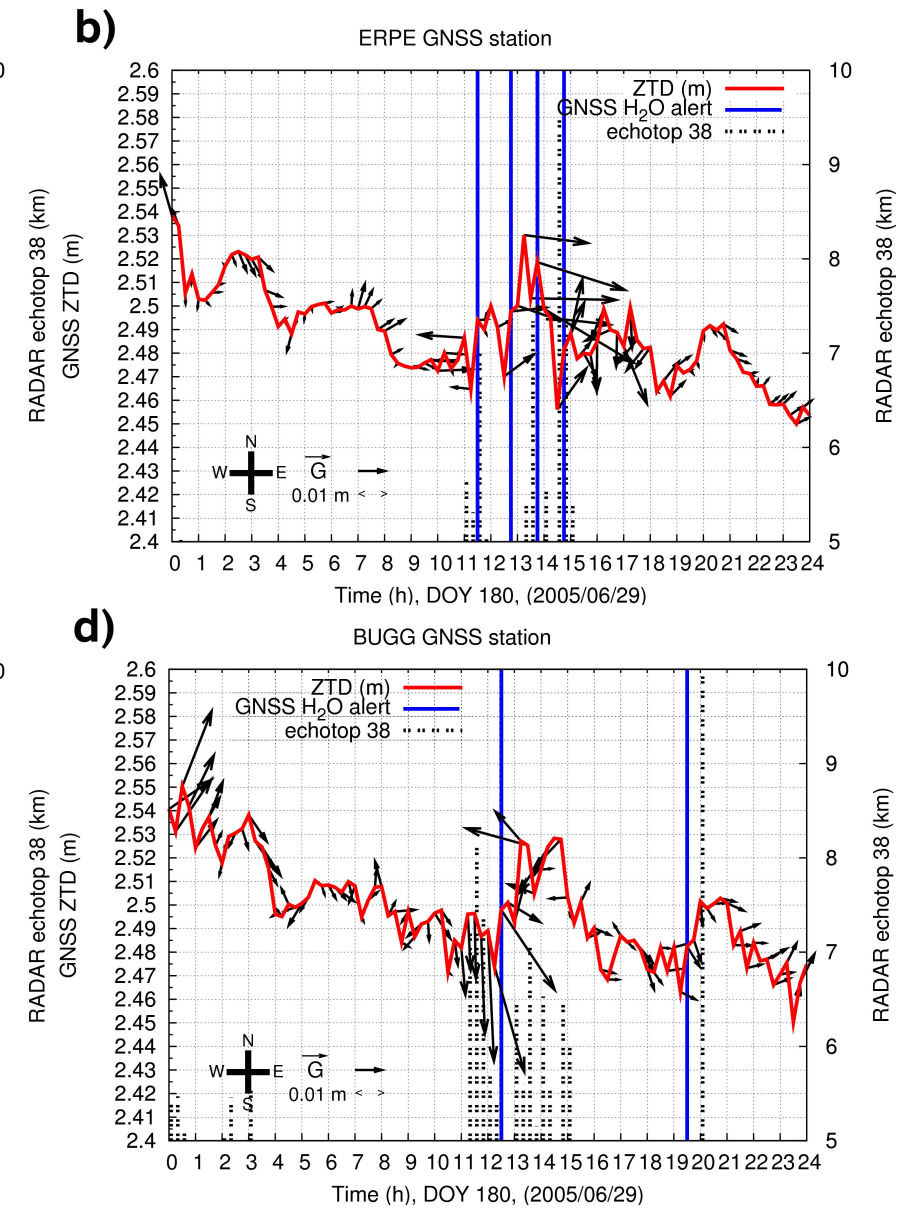

Figure 11. Time series of ZTD and gradients (a) for NAMR, (b) ERPE, (c) GERA, and (d) BUGG stations (29 June 2005). GNSS $\mathrm{H}_{2} \mathrm{O}$ alerts are shown by blue dotted lines. Altitudes of the highest $38 \mathrm{dBZ}$ radar echoes are plotted for values over $5 \mathrm{~km}$ (black dash line).

found a low Pearson correlation coefficient between radar precipitation and GNSS gradient amplitudes for all GNSS stations.

\subsection{Improvement of the water vapour field using GNSS gradients}

Using the Belgian dense network of GNSS stations (baselines from 5 to $30 \mathrm{~km}$; see Fig. 8) and observations with a time resolution of $15 \mathrm{~min}$, it is possible to characterise the water vapour field of the troposphere. The initiation of a convective system takes place for some cases in an area of a few square kilometres; for this reason we have combined ZTD and gradients to improve the spatial resolution of our water vapour field assessments. Our strategy is the following: considering the axis indicated by a gradient $\vec{G}$, two additional ZTD pseudo-observations have been considered (one wetter in the direction of the vector and the other one drier in the opposite direction). Our tests on the Belgian dense network (Neméghaire and Brenot, 2010) have shown that $10 \mathrm{~km}$ on either side of the GNSS site is the most relevant dis- tance to detect small scale structures of the troposphere (of a few kilometres). GNSS gradients (differential values in the zenith direction) can be propagated horizontally by multiplying this contribution by the distance in kilometres (Walpersdorf et al., 2001). Then additional pseudo-observations of ZTD can be considered in our 2-D interpolated field with an adjustable tension continuous curvature surface gridding algorithm (Smith and Wessel, 1990). To avoid the signature of orography in ZTD measurements, we have applied an altitude correction (hydrostatic correction) to sea level, as introduced by Saastamoinen (1972) and improved by Vedel et al. (2001). In Fig. 10, we can clearly see an improvement of the resolution of the water vapour field observed by GNSS. The new structures of water vapour identified in Fig. 10b are in agreement with the line of convergence shown by our meso-scale analysis (see Fig. 3).

The meteorological situation and the location of water vapour blobs observed by GNSS are in a good agreement with radar precipitation. We can see in Fig. 1 that strong horizontal GNSS gradients are observed when significant hourly precipitation is recorded by meteorological radar from 12:00 


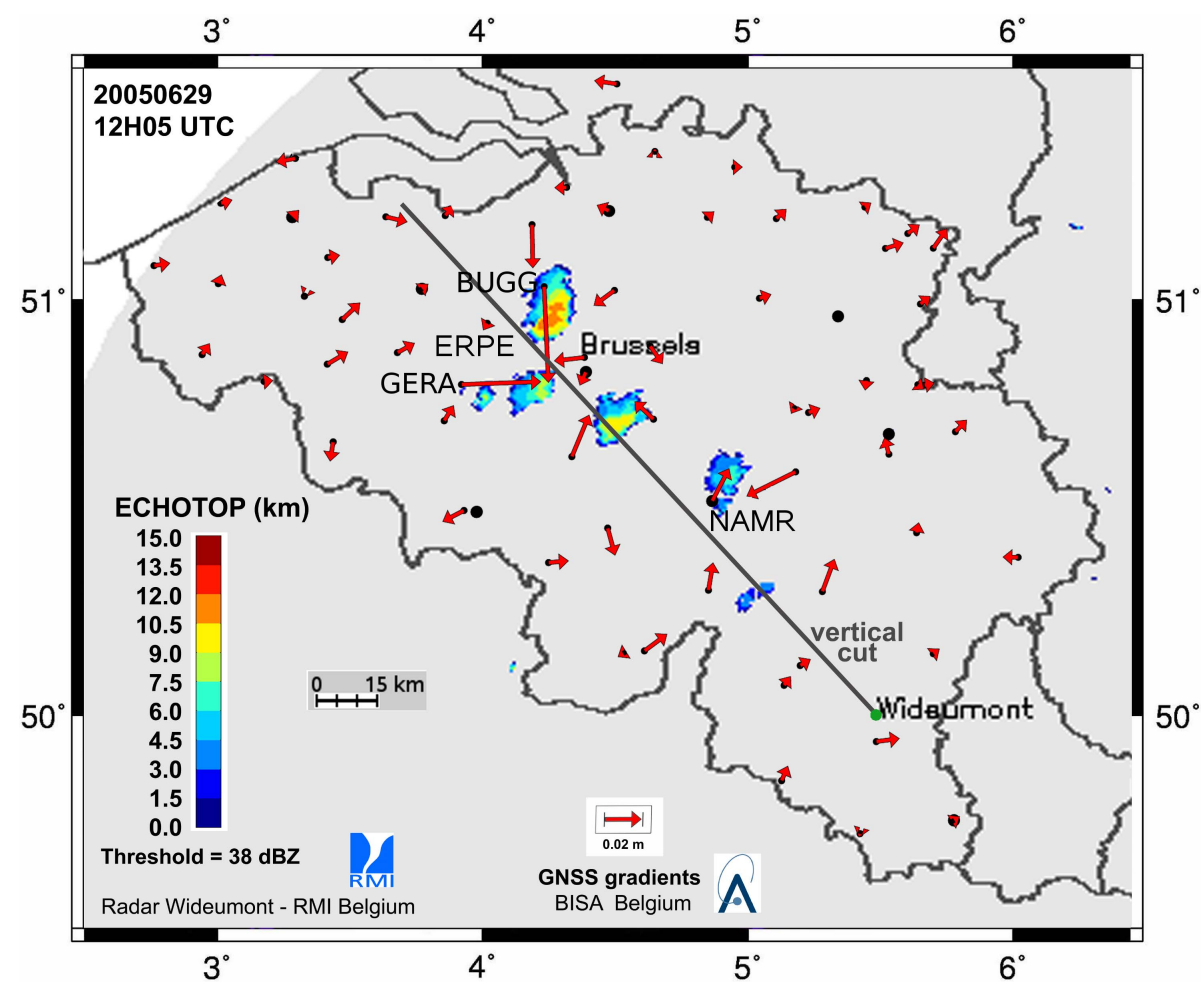

Figure 12. Altitude of the highest $38 \mathrm{dBZ}$ radar echo on 29 June 2005 at 12:05 UTC. The black line shows the location of the vertical cut of radar reflectivity presented in Fig. 13. GNSS gradients are plotted with red arrows on stations (small black circles). The main Belgium cities are shown by big black circles and the Wideumont weather radar with a green circle.

to $16: 00$ UTC. This is evidence that the water vapour field was characterised by a strong anisotropy during this period (see Fig. 10). The next step of our study is to implement $\mathrm{H}_{2} \mathrm{O}$ alerts according to a specific configuration of the GNSS water vapour field.

\section{Implementation of $\mathrm{H}_{2} \mathrm{O}$ alert by GNSS}

A meticulous observation of ZTD and gradient time series has shown that for some regions a typical configuration can be observed before initiation of deep convection. This configuration is described by a significant local decrease of ZTD (drier region) followed by a strong increase of ZTD (wetter region). This dry/wet contrast evolution is illustrated in Figs. 10b and 11 around 12:00 UTC for 4 stations of the Belgian dense network.

ZTD and gradients are estimated in the zenith direction considering all visible satellites. For a tropopause around $10 \mathrm{~km}$ of altitude and a cut-off angle of $10^{\circ}$, the radius of the tropospheric area considered by GNSS does not exceed $50 \mathrm{~km}$. Nevertheless, the column of water vapour is of interest for our study. Looking for the cone of influence of water vapour above the receiver, we can use a water vapour scale height of around $2.5 \mathrm{~km}$ and then, if we assume an av- erage satellite elevation angle of around $30^{\circ}$, the cone radius is about $10 \mathrm{~km}$.

A gradient $\overrightarrow{\vec{G}}$ with an amplitude of $0.01 \mathrm{~m}$ in the east direction means that the ZTD in the east direction is higher (for example about $0.01 \mathrm{~m}$ at $25 \mathrm{~km}$ ). We can easily see in Fig. 11 what the ZTD values are around Erpe (ERPE), Namur (NAMR), Geraardsbergen (GERA) and Buggenhout (BUGG) stations in the direction of a gradient because ZTD and the gradient are plotted on the same scale.

Using the improvement by horizontal GNSS gradients of the 2-D field of ZTD, which can be used to estimate the water vapour field (see Brenot et al., 2006), we have established a gridded map of GNSS alerts with a high resolution (pixels of $3 \mathrm{~km} \times 3.5 \mathrm{~km}$ ). The conditions to obtain a $\mathrm{H}_{2} \mathrm{O}$ alert for a pixel at time $T$ are the following:

- a ZTD-decrease of $0.008 \mathrm{~m}$ from $T-30 \mathrm{~min}$ to $T-15 \mathrm{~min}$

- followed by a ZTD-increase of $0.015 \mathrm{~m}$ from $T-15 \min$ to $T$

$\mathrm{H}_{2} \mathrm{O}$ alerts are shown by blue lines in Fig. 11. GNSS observations have been calculated every $15 \mathrm{~min}$. 


\section{Indicators of deep convection}

We have considered two external meteorological indicators of deep convection. The first one is based on reflectivity observations from a C-band weather radar located at Wideumont in the south of Belgium. The radar performs a 5elevation scan every $5 \mathrm{~min}$ and a 10 -elevation scan every $15 \mathrm{~min}$. The latter is used to derive echo top values, which gives for a given threshold the maximum height where reflectivity values at least equal to this threshold are measured (Delobbe and Holleman, 2006). In this study we use a $38 \mathrm{dBZ}$ threshold and we consider that a $38 \mathrm{dBZ}$ echo top higher than $5 \mathrm{~km}$ represents a good indicator of deep convection.

During the rainfall event of 29 June 2005, we can see that at 12:05 UTC radar echoes top indicate deep convection for 3 cells around Brussels (see Fig. 12). We have seen in Sect. 3.2, referring to Figs. 1 and 11, that strong activity has been recorded by radar hourly precipitation (up to $55 \mathrm{~mm} \mathrm{~h}^{-1}$, with daily precipitation up to $95 \mathrm{~mm} \mathrm{day}^{-1}$ for some regions) and GNSS horizontal gradients (amplitude up to $0.045 \mathrm{~m}$, which means about $0.25 \mathrm{~m}$ at $10^{\circ}$ of elevation) between 12:00 and 15:00 UTC on 29 June. At the same time (Figs. 11 and 12), high values of the GNSS horizontal gradients point in the direction of the convective cells where the maximum water vapour content and the convection occurred.

Figure 13 shows a vertical cut of radar reflectivity. GNSS gradient of the BUGG station points the local tropospheric anisotropy towards the convective cell located between Brussels and Buggenhout. This convective cell had a vertical extension of more than $12 \mathrm{~km}$. The least-square adjustment of GNSS gradients considers all the visible GNSS satellites; note that for the station of Brussels located close to several convective systems (see Fig. 13), no significant anisotropy is observed by the gradient. By contrast, the GERA station observes a strong local anisotropy. We can see in Fig. 13 that all high values of the gradients point in the direction of cells identified by radar (see, for example, NAMR station).

The second indicator of deep convection that we use is the infrared radiance from the SEVIRI instrument on Meteosat Second Generation (Chanel 09). The observations used in this study are expressed in digital counts (DC). For the $10.8 \mu \mathrm{m}$ IR channel, the conversion of a radiance in DC $\left(R_{\mathrm{DC}}\right)$ in a radiance in the International System of units $\left(R_{\mathrm{SI}}\right)$ is the following:

$R_{\mathrm{SI}}=R_{\mathrm{DC}} \cdot$ gain + offset

where the "gain" is 0.205034 and the "offset" -10.456757 . The observations of radiance allow us to estimate cloud top temperatures (CTT). This parameter is more commonly used by meteorologists. The conversion of the radiance in CTT (expressed in Kelvins) is the following:

$$
\mathrm{CTT}=\frac{c_{2} \cdot v}{\ln \left(1+\frac{c_{1} v^{3}}{R_{\mathrm{SI}}}\right)}
$$

Table 1. Conversion table (channel 09 of SEVIRI) of IR radiance in digital counts $\left(R_{\mathrm{DC}}\right)$ to IR radiance in the International System of units $\left(R_{\mathrm{SI}}\right)$, and to CTT (in $\left.\mathrm{K}\right)$.

\begin{tabular}{ccc}
\hline $\begin{array}{c}\text { Radiance } R_{\mathrm{DC}} \\
\text { (in DC) }\end{array}$ & $\begin{array}{c}\text { Radiance } R_{\mathrm{SI}} \\
\text { (in } \mathrm{W} \mathrm{m}^{-2} \mathrm{sr} \mathrm{cm}^{-1} \text { ) }\end{array}$ & $\begin{array}{c}\text { CTT } \\
\text { (in K) }\end{array}$ \\
\hline 160 & 22.3487 & 220.7795 \\
200 & 30.5500 & 232.7423 \\
240 & 38.7514 & 242.7394 \\
280 & 46.9528 & 251.4513 \\
320 & 55.1541 & 259.2471 \\
360 & 63.3555 & 266.3520 \\
\hline
\end{tabular}

where $\quad v\left(=930.659 \mathrm{~cm}^{-1}\right)$ is the central wave number of the $10.8 \mu \mathrm{m}-\mathrm{IR}$ band, and $c_{1}=0.00001191066 \mathrm{~mW}\left(\mathrm{~m}^{-2} \mathrm{srcm}^{-4}\right)$ and $c_{2}=1.438833$ $\mathrm{K} \mathrm{cm}^{-1}$ are fixed values.

If the effective radiance $\left(R_{\mathrm{DC}}\right.$ is less than $200 \mathrm{DC}$ $\left(\sim 30.55 \mathrm{~W} \mathrm{~m}^{-} 2 \mathrm{sr}-1 \mathrm{~cm}^{-1}\right)$, we consider that deep convection took place. A radiance of $200 \mathrm{DC}$ corresponds to a CTT of $232.7423 \mathrm{~K}$ (see Table 1).

The region for which SEVIRI identifies deep convection (Fig. 14) is from blue to green to yellow. Over Belgium, the SEVIRI resolution is about $3 \mathrm{~km}(\mathrm{E}-\mathrm{W}) \times 5 \mathrm{~km}(\mathrm{~N}-\mathrm{S})$. The infrared $10.8 \mu \mathrm{m}$ channel has been selected because the channel presents the best correlation with the cloud top height. In the most national meteorological services, this channel is usually used to detect and track convective systems. The water vapour indicated by GNSS gradients does not always correspond to the location of the convective cells and the clouds with the highest tops identified by SEVIRI. Nevertheless, during this event, high GNSS gradients (values up to $0.04 \mathrm{~mm}$ ) always point in the direction of region where clouds with high top altitudes ( $>5 \mathrm{~km}$ ) have been observed by SEVIRI less than $45 \mathrm{~min}$ after. For these regions, the CTT are less than $232.5 \mathrm{~K}$ (see Figs. 14 and 15). Even when a Pearson negative correlation of 0.36 is obtained between CTT and horizontal GNSS gradient amplitudes, we find a good correspondence between low CTT and high gradient amplitudes. In fact, $65 \%$ of GNSS sites with gradient amplitudes higher than $0.02 \mathrm{~m}$ show IR radiances under $220 \mathrm{DC}$ (which corresponds to a CTT of about $238 \mathrm{~K}$ ).

\section{First results of $\mathrm{GNSS}_{2} \mathrm{O}$ alert validation}

\subsection{GNSS $\mathrm{H}_{2} \mathrm{O}$ alerts from reference post-processing}

To estimate the score of our $\mathrm{H}_{2} \mathrm{O}$ GNSS alerts, we consider that an alert is validated if an indicator of deep convection (by radar and/or by SEVIRI) is observed during the next 50 min. To validate our $\mathrm{H}_{2} \mathrm{O}$ alert, the altitude of the $38 \mathrm{dBZ}$ radar echo and the SEVERI infrared radiance have 


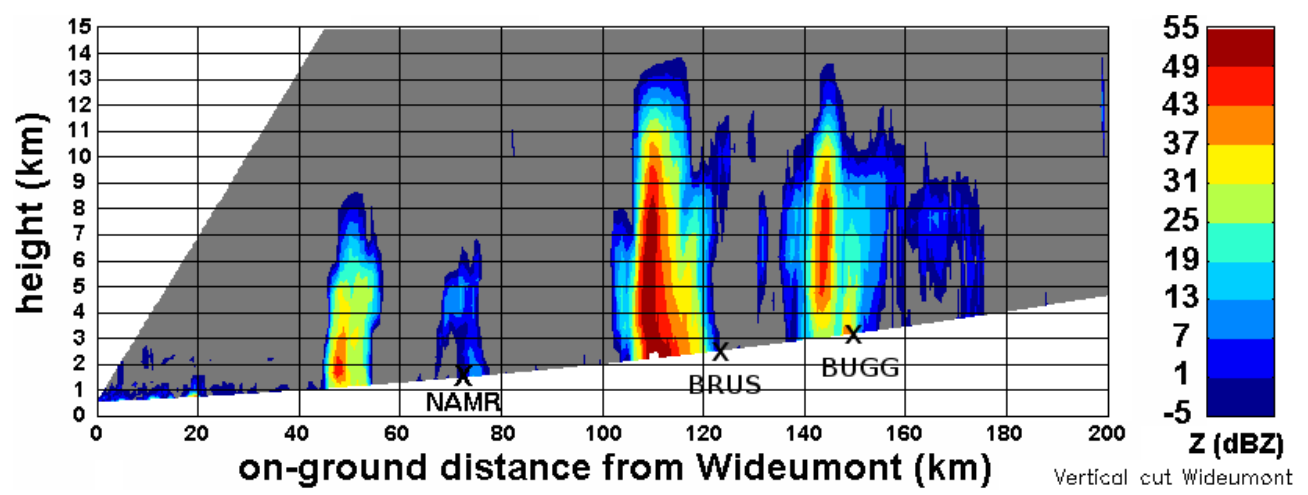

Figure 13. Radar imaging of a vertical cut of reflectivity (in dBZ up to $15 \mathrm{~km}$ ) from Wideumont radar to a distance of $200 \mathrm{~km}$ in the northwest direction (12:05 UTC, 29 June 2005). Projections of the BRUS and BUGG stations (respectively $6 \mathrm{~km}$ and $13 \mathrm{~km}$ distant) on this axis are plotted on this graph.

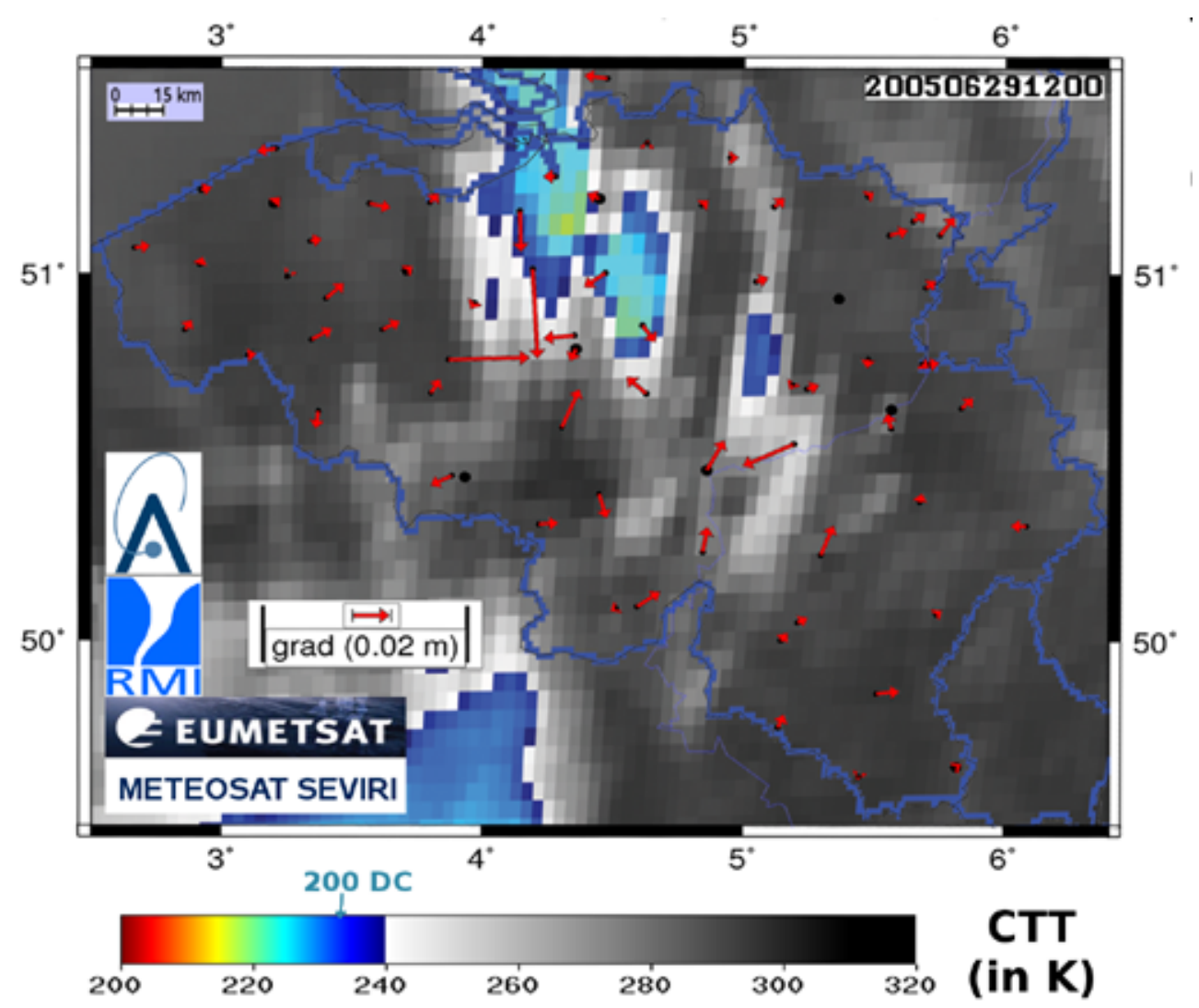

Figure 14. CTT of the $10.8 \mu \mathrm{m}$ channel of SEVIRI (in Kelvins) and GNSS gradients plotted with red arrows on stations (small black circles) at 12:05 UTC (29 June 2005). Cities are in larger black circles.

been determined for the same grid. For this study, we have considered radar and SEVIRI observations every $15 \mathrm{~min}$ (at 05, 20, 35 and 50 min each hour). GNSS measurements and alerts were obtained every $15 \mathrm{~min}$ (at $0,15,30,45 \mathrm{~min}$ ).

The more active period of this event was between 11:00 and 16:00 UTC on 29 June 2005. To show the application for nowcasting of our alert system, our improved ZTD 2-D fields, our GNSS $\mathrm{H}_{2} \mathrm{O}$ alert 2-D fields, radar echoes top, and
2-D fields of SEVIRI radiances from 10:45 to 13:30 UTC are presented in Fig. 15. GNSS gradients are plotted on our interpolated ZTD fields (see Sect. 3.3). For $\mathrm{H}_{2} \mathrm{O}$ alert, radar echoes top, and SEVIRI IR radiance fields, a grid of $3 \mathrm{~km} \times 3.5 \mathrm{~km}$ (size of pixel) is used to obtain images. Twelve periods are shown in this figure (every $15 \mathrm{~min}$ ). We will give a description of these times using all 2-D fields presented in Fig. 15. 


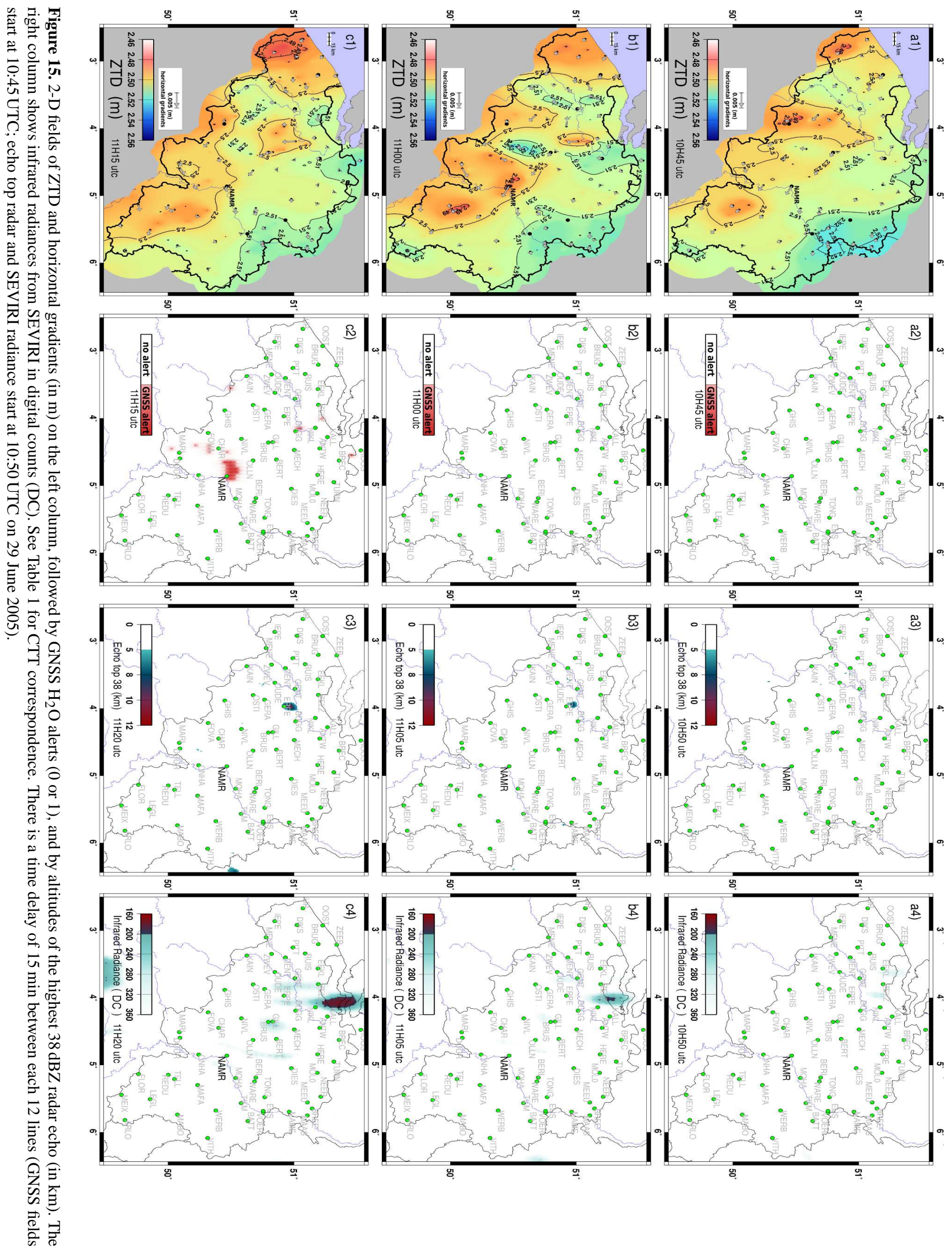




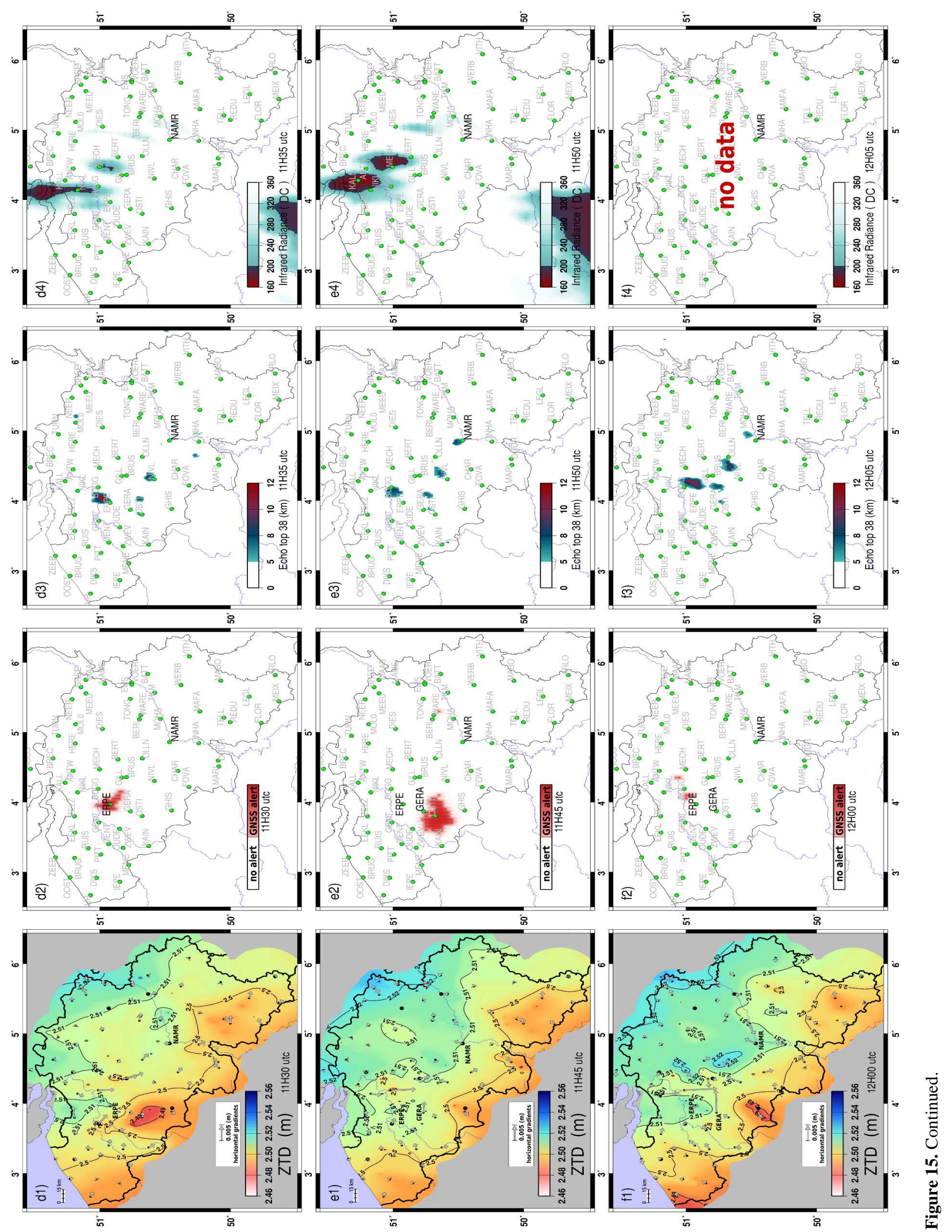




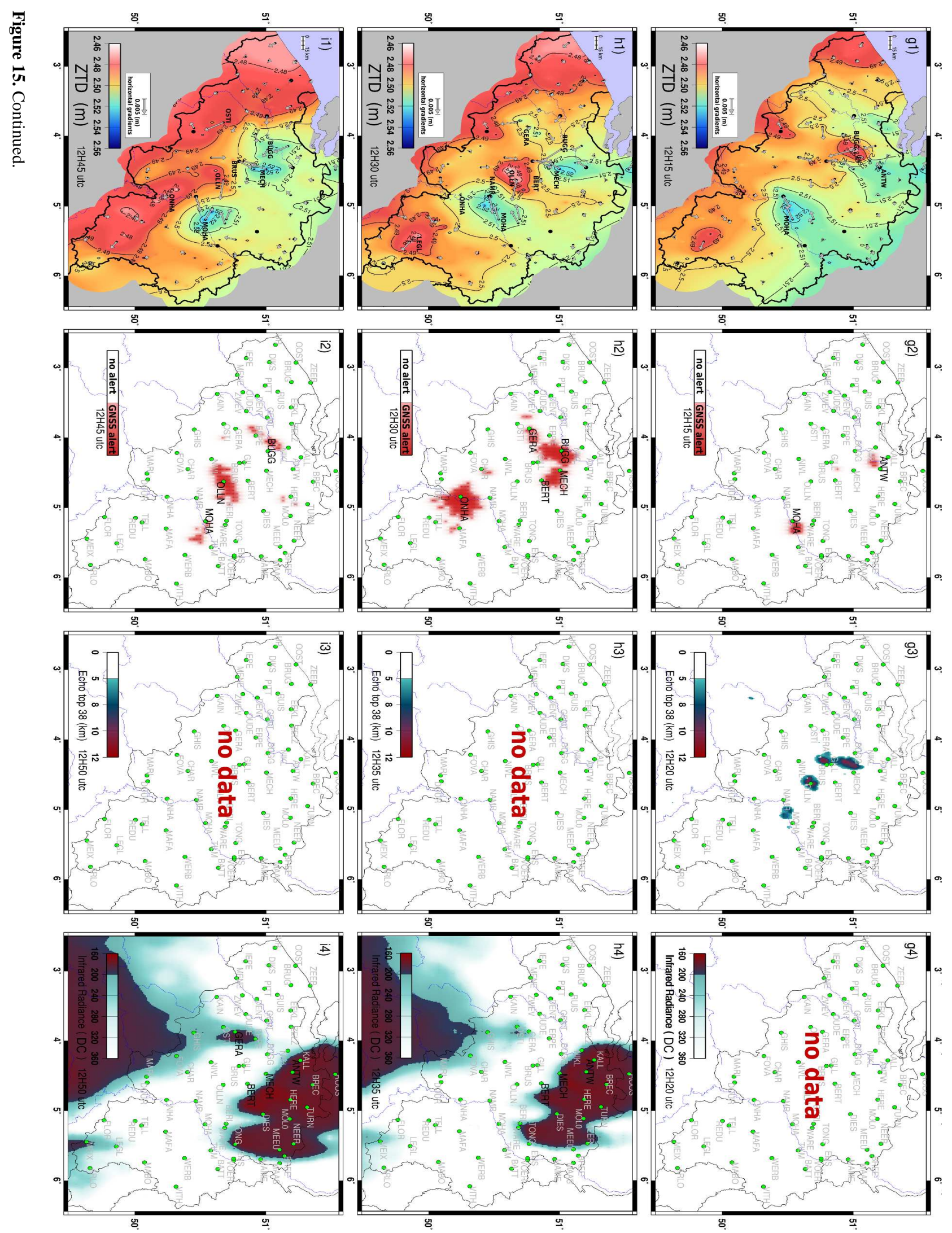




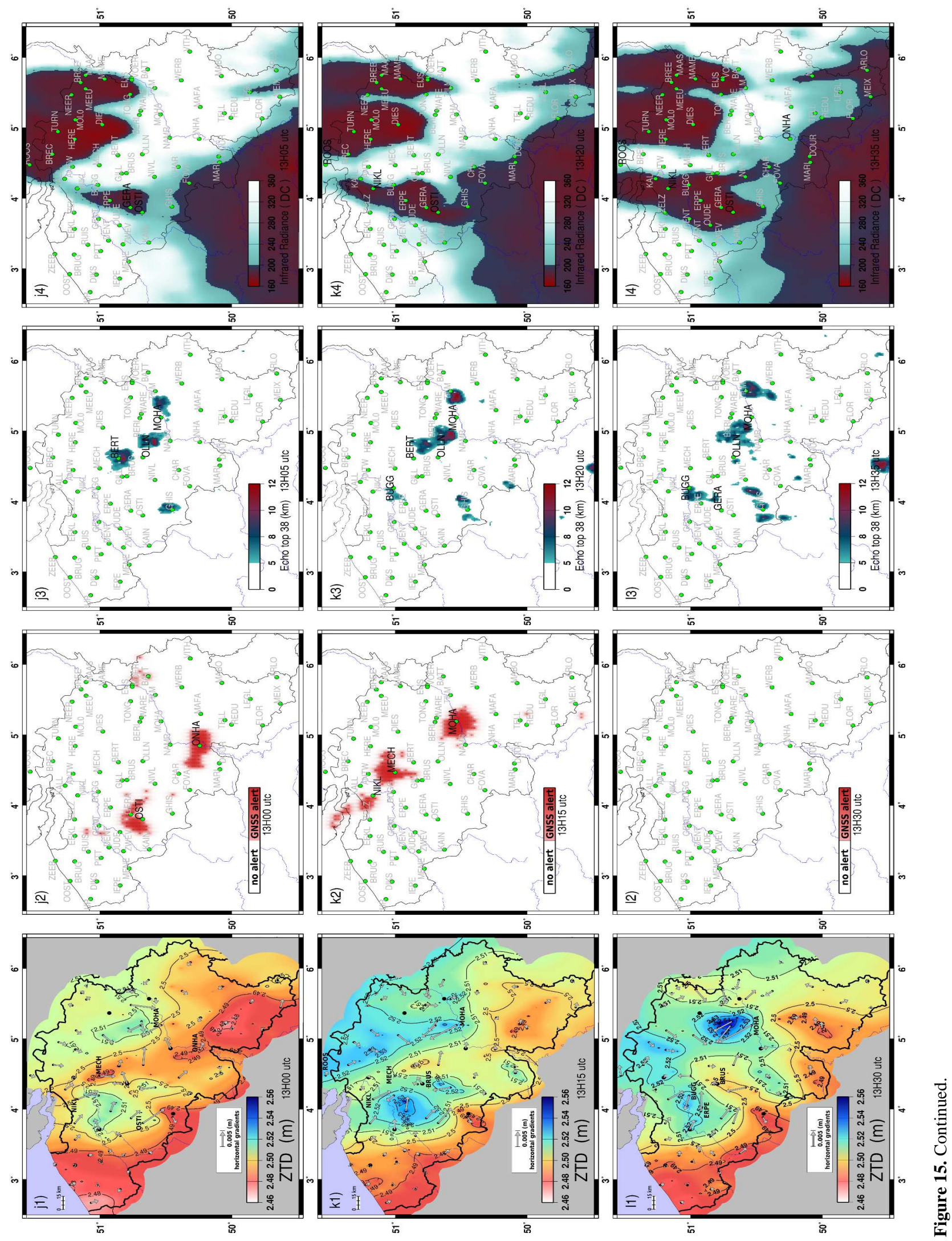


Period a and b: No GNSS alert was observed at 10:45 and 11:00UTC, but we noted that a strong decrease of water vapour content took place around NAMR station at 11:00 UTC. To the east of the NAMR region, a blob of water vapour was identified. To the east of the NAMR region, a blob of water vapour was identified. Then, a dry/wet contrast between the wet region and the drier nearby region was observed. Further on in this study, we will call this dry/wet contrast, which can take place in space and time, a "dry/wet dipole".

Period c (11:15 UTC): There were 25 pixels with GNSS $\mathrm{H}_{2} \mathrm{O}$ alerts around NAMR. We noted an increase in the water vapour field on the north-west side of NAMR.

Period d (11:30UTC): There were 24 pixels with $\mathrm{H}_{2} \mathrm{O}$ alerts around ERPE (on the north and the south-east side). An increase of ZTD (and water vapour content) is associated with the development of a deep cloud cell, entrained by the low troposphere flux of water vapour coming from the north and converging into this region. The large vertical extension of this cloud cell was confirmed by IR radiance from SEVIRI showing low cloud top temperature.

Instability was shown by radar echoes top for this zone. A strong decrease of the water vapour content was observed to the south of ERPE (dry/wet dipole).

Period e (11:45 UTC): There were 62 GNSS alerts around GERA (strong increase in the water vapour field). We observed an increase of the water vapour contents of all the stations located on the east side of the GERA-NAMR line. Convection started around NAMR.

Period $f$ (12:00 UTC): GNSS gradients were observed with a strong water vapour content to the south-east of ERPE. Strong precipitation and convection were shown by radar with a high vertical extension (see Fig. 13).

Period g (12:15 UTC): There were 6 GNSS alerts on the south side of ANTW, and 14 alerts on the east side of MOHA. A strong increase in the water vapour field was observed around ANTW and MOHA stations. We can see evidence of a dry/wet dipole between BUGG and ANTW regions. BUGG station measured a strong GNSS gradient.

Period h (12:30UTC): There were more than 80 alerts around BUGG which took place after a dry/wet contrast and a strong increase of the water vapour content. There were also more than 80 alerts around ONHA station with an increase in the water vapour field of this region. We noted a dry/wet dipole between OLLN and NAMR. Strong horizontal gradients of delay pointed in the direction of this wet area. Water vapour structures and clouds were observed by SEVIRI around ANTW, MECH and BERT stations.

Period i (12:45 UTC): There were about 60 alerts around OLLN, with a dry/wet dipole between ONHA and MOHA stations. We observed strong water vapour contents and gradients around MECH-BUGG and MOHA stations. Convection was detected by SEVIRI around GERA station.

Period j (13:00 UTC): There were about 50 alerts around OSTI with a strong increase of the water vapour contents in the triangle OSTI-NIKL-MECH. On the other hand, a dry patch was shown (ZTD field) around MECH station. A dry/wet dipole was observed between this patch and the wet triangle. About 50 alerts are generated around ONHA with an increase of the water vapour contents in this region. Convection was detected by echoes top radar around BERT, OLLN and MOHA stations. Convection was also detected by IR radiance around OSTI and GERA stations.

Period k (13:15 UTC): There were more than 70 alerts around $\mathrm{MECH}$, with an increase of the water vapour field to the east of this station. Wet regions detected by ZTD corresponded to regions with low IR radiances (convection identified by SEVIRI). More than 70 alerts took place around MOHA with an increase of the water vapour field in this region. Strong precipitation and convection were detected by radar around MOHA, OLLN and BUGG stations.

Period 1 (13:30 UTC): No alerts. At this time several cells with strong vertical extension were observed by the radar. Convective cells with high CTT $(<235 \mathrm{~K})$ were detected by SEVIRI on the south side of Belgium, as well as between ROOS and OSTI stations and on the north-east side of Belgium.

The analysis of Fig. 15 is a bit exhaustive, but there is considerable information for nowcasting. To summarise, the analysis of these periods shows that GNSS $\mathrm{H}_{2} \mathrm{O}$ alerts are the result of dry/wet contrasts in time (strong increase and decrease) and dry/wet contrasts in space (dipole). This can be the result of a transfer of water vapour in this region, or simply be the rise of moist air above the GNSS antenna. We observed strong amplitudes of gradients pointing towards wet areas with a strong instability. This shows the application of these observations for nowcasting. The statistical results and validation of our GNSS $\mathrm{H}_{2} \mathrm{O}$ alerts generated are shown in Table 2 . We can see that $72 \%$ of our alerts are validated by radar and SEVIRI (score of 39\% for radar and $56 \%$ for SEVIRI) for this period. The location of convection indications from radar and SEVIRI do not always correspond. Table 3 shows statistical results for the whole period under study. Using observations with a time resolution of $15 \mathrm{~min}$, we have interpolated linearly ZTD and gradient measurements for a time resolution of $5 \mathrm{~min}$. We can follow precisely the evolution of the water vapour field and the application of our GNSS alerts for nowcasting. When the weather is quiet with no indication of deep convection, no alert was generated by our system. Rain was recorded by rain gauges and radar on 1 and 2 July (passage of a front of cloud system with a maximum daily local precipitation of $15 \mathrm{~mm} \mathrm{day}^{-1}$ ). No GNSS alert took place for these days. No dry/wet dipole and no strong contrast in time in the water vapour field were observed by GNSS. We can see that the linear increase of ZTD and gradient time resolution can improve our GNSS alert system. In fact, the number of alerts increased and in some cases, alerts took place earlier.

To see the impact of the quality of the satellites orbits on ZTD and gradients calculations, we have compared 
Table 2. Statistical results between 10:45 and 13:30 UTC on 29 June 2005 . For each $\mathrm{H}_{2} \mathrm{O}$ alert (pixel), if deep convection is indicated by radar and/or SEVIRI, one count is obtained. Final scores are set with a normalisation in percentage.

\begin{tabular}{ccrrr}
\hline Periods & $\begin{array}{c}\text { Number of } \\
\mathrm{H}_{2} \mathrm{O} \text { alert }\end{array}$ & $\begin{array}{r}\text { Score } \\
\text { (radar) }\end{array}$ & $\begin{array}{r}\text { Score } \\
\text { (SEVIRI) }\end{array}$ & $\begin{array}{r}\text { Final } \\
\text { Score }\end{array}$ \\
\hline 29 Jun 2005 10:45 & 0 & $/$ & $/$ & $/$ \\
29 Jun 2005 11:00 & 0 & $/$ & $/$ & $/$ \\
29 Jun 2005 11:15 & 32 & $50.0 \%$ & $9.4 \%$ & $53.1 \%$ \\
29 Jun 2005 11:30 & 24 & $62.5 \%$ & $0.0 \%$ & $62.5 \%$ \\
29 Jun 2005 11:45 & 63 & $52.4 \%$ & $57.1 \%$ & $62.0 \%$ \\
29 Jun 2005 12:00 & 6 & $100.0 \%$ & $83.3 \%$ & $100.0 \%$ \\
29 Jun 2005 12:15 & 21 & $52.4 \%$ & $33.3 \%$ & $85.7 \%$ \\
29 Jun 2005 12:30 & 181 & $19.4 \%$ & $43.6 \%$ & $50.3 \%$ \\
29 Jun 2005 12:45 & 80 & $76.3 \%$ & $45.0 \%$ & $91.3 \%$ \\
29 Jun 2005 13:00 & 115 & $32.2 \%$ & $94.8 \%$ & $95.7 \%$ \\
29 Jun 2005 13:15 & 167 & $33.1 \%$ & $67.0 \%$ & $76.8 \%$ \\
29 Jun 2005 13:30 & 0 & $/$ & $/$ & $/$ \\
\hline all this period & 689 & $39.1 \%$ & $56.1 \%$ & $72.2 \%$ \\
\hline
\end{tabular}

ultra-rapid orbits (IGSU) with our reference calculations with the final orbits (IGSF), both provided by the International GNSS Service (http://igscb.jpl.nasa.gov). We find that these measurements are extremely close (see red and black lines in Fig. 16). For a calculation with 35 stations during one week of data, the mean bias and the standard deviation are less than $0.0001 \mathrm{~m}$ for ZTD and gradients. An equivalent score for the validation of $\mathrm{H}_{2} \mathrm{O}$ alerts is found. In the next session the ultra-rapid orbits will be used to process fast ZTD and gradient measurements.

\subsection{GNSS $\mathrm{H}_{2} \mathrm{O}$ alerts from fast calculations}

To estimate ZTD and gradients in an operational way, the use of ultra-rapid orbit is required. In this section, we have used the IGSU orbits. Because the operational use of GNSS observations required a very short time of calculations, we decided to process sessions of $6 \mathrm{~h}$ (and not $12 \mathrm{~h}$ like for the post-processing). Six hours is the minimum time to be able to resolve properly the ambiguities of the GNSS signals (see Sect. 3.2). The time of calculations (by least-square adjustment) increases non-linearly in function of the number of stations considered. With 20 stations in a run (10 fiducial stations, 4 long-distance stations, and 6 stations of the Belgian network; see Sect. 3.1), this time is about $5 \mathrm{~min}$. Twelve processes have to be run in the same time to obtain the GNSS measurements of the whole Belgium dense network (70 stations). The fast calculations we present in this section have been done a posteriori. Nevertheless, the quality of these measurements are equivalent to near real-time observations. We can see in Fig. 16 that there is a satisfactory agreement between the reference post-processed ZTD and gradients of ERPE station and the fast ones. To complete our ZTD comparison, we processed one week of data,

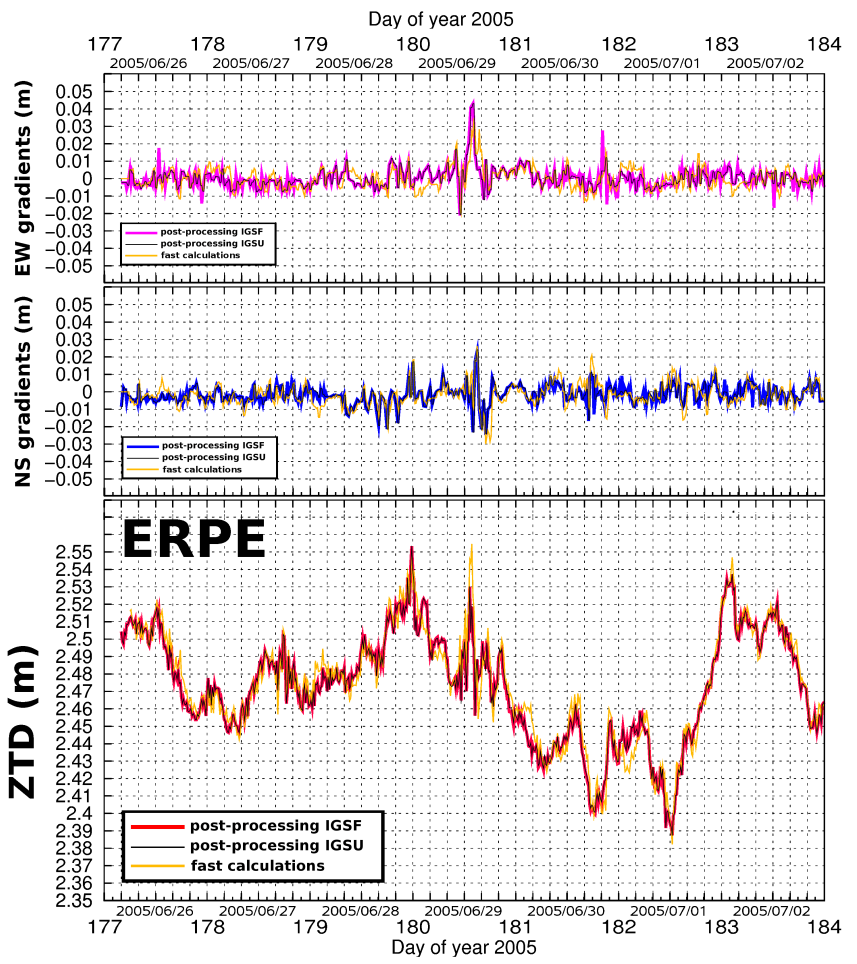

Figure 16. Time series of ZTD and gradients (from 26 June to 3 July 2005) from post-processed (final orbits IGSF and ultra-rapid orbits IGSU) and from fast calculations.

with 7 Belgian stations considered: GENT, BUGG, GERA, ERPE, GILL, OUDE, and also BRUS, which is one on the fiducial stations (see Fig. 8). The mean biases (and standard deviations) between fast and post-processed ZTD and gradients (millimetric zenith estimations) observations are, respectively, $0.002( \pm 0.008) \mathrm{m}$ and $0.001( \pm 0.004) \mathrm{m}$. No sliding window strategy was considered (which is usually used to avoid the "side effect" of the measurements at the beginning and at the end of a session). ZTD and gradients were estimated every $15 \mathrm{~min}$ in one session. Every $5 \mathrm{~min}$ a session was run. The fast ZTD and gradient measurements we considered for a given time were the last ones (at the end) of each session. A very good agreement has been obtained between fast and post-processed ZTD (less than $10 \mathrm{~mm}$ ) and gradients (less than $5 \mathrm{~mm}$ in the zenith direction; about $25 \mathrm{~mm}$ at $10^{\circ}$ of elevation). Note that the fast measurements (ZTD and gradients) are generally higher than the reference observations of the post-processing. The time of calculation for one session of post-processing is $2 \mathrm{~h}$ (giving ZTD and gradient observations for 20 Belgian stations every $15 \mathrm{~min}$, for a time-window of $4 \mathrm{~h}$ ). For fast measurements, this time is about $5 \mathrm{~min}$ (giving ZTD and gradients for 6 Belgian stations; observations every 15 min during $6 \mathrm{~h}$ with only the last period of measurements that we consider).

In Table 4, we present our first statistical results of the validation of $\mathrm{H}_{2} \mathrm{O}$ alerts established from fast ZTD and 
Table 3. Number and score of our $\mathrm{H}_{2} \mathrm{O}$ alert strategy (GNSS observations from 26 June 2005 to 2 July 2005). The time resolution of GNSS observations is $15 \mathrm{~min}$. In brackets are shown results when GNSS observations are interpolated linearly every $5 \mathrm{~min}$.

\begin{tabular}{ccccc}
\hline Periods & $\begin{array}{c}\text { Number of } \\
\mathrm{H}_{2} \mathrm{O} \text { alerts }\end{array}$ & $\begin{array}{c}\text { Score } \\
\text { (radar) }\end{array}$ & $\begin{array}{c}\text { Score } \\
(\text { SEVIRI })\end{array}$ & $\begin{array}{c}\text { Final } \\
\text { Score }\end{array}$ \\
\hline 26 Jun 2005 & $0(0)$ & $/$ & $/$ & $/$ \\
27 Jun 2005 & $0(0)$ & $/$ & $/$ & $/$ \\
28 Jun 2005 & $798(1853)$ & $34 \%(31 \%)$ & $70 \%(71 \%)$ & $78 \%(75 \%)$ \\
29 Jun 2005 & $2821(6384)$ & $48 \%(44 \%)$ & $82 \%(84 \%)$ & $89 \%(87 \%)$ \\
30 June 2005 & $0(0)$ & $/$ & $/$ & $/$ \\
1 Jul 2005 & $0(0)$ & $/$ & $/$ & $/$ \\
2 Jul 2005 & $0(0)$ & $/$ & $/$ & $/$ \\
\hline All days & $3619(8237)$ & $45 \%(41 \%)$ & $79 \%(81 \%)$ & $86 \%(84 \%)$ \\
\hline
\end{tabular}

gradient measurements. The period considered is between 10:45 and 13:30 UTC on 29 June 2005. Reference and fast post-processed measurements results (i. e. number of alerts and final scores of the validation using echo top radar and IR radiance from SEVIRI) are both presented with a time resolution of $5 \mathrm{~min}$. The number of alerts and the scores shown in brackets in Table 4 have been obtained without the use of pseudo-ZTD established from gradients. We see that for both types of calculations, the total number of alerts is 40 $45 \%$ less without the use of gradients. For post-processed GNSS measurements, the score with gradients and pseudoZTD is slightly better (69.6\% only with ZTD; $76.4 \%$ with gradients). We have seen in Table 3 that an interpolation of ZTD and gradients measurements from $15 \mathrm{~min}$ to $5 \mathrm{~min}$ increases the number of alerts. Logically, a time resolution of 5 min would show more alerts (1003) than a time resolution of 15 min (see Table 2 with a total number of alerts of 689). For the fast measurements, the score with and without gradient are good and equivalent (respectively $66.5 \%$ and $67.4 \%$ ), which means that our method can also be used without gradients. Nevertheless, the number of alerts is $45 \%$ smaller without the use of gradients. This shows the advantage of using gradients to improve the spatial resolution and the number of our GNSS $\mathrm{H}_{2} \mathrm{O}$ alerts. As an example, Fig. 17b and c show the localisation of the $\mathrm{H}_{2} \mathrm{O}$ alerts generated on 29 June at 12:35 UTC without and with the use of gradients. We can see a good agreement between the alerts generated by reference post-processing and by fast calculations (see Fig. 17a and c). This shows the first validation of our method $\left(\mathrm{H}_{2} \mathrm{O}\right.$ alerts) using fast observations, which are similar to operational ones.

\section{Conclusion and perspectives}

The aim of this paper was to see if preliminary signs of the initiation of deep convection can be established from postprocessed meteorological GNSS observations (zenith total delay of the neutral atmosphere, called ZTD or commonly "tropospheric delay", and horizontal delay gradients or commonly called "wet gradients"). Our study was focussed on the rainfall event of the 28-29 June 2005 over Belgium. To summarize this rainfall event, between 10:00 and 16:00 UTC on 29 June, the surface analysis and the CAPE/CIN fields from radiosondes and models (ALADIN and ECMWF) indicated a (severe) convective episode over Belgium (with a CAPE of $868 \mathrm{~J} \mathrm{~kg}^{-1}$ and a CIN of $1.05 \mathrm{~J} \mathrm{~kg}^{-1}$ measured by radiosonde over Brussels on 29 June at 12:00 UTC). Lines of convergence had taken place in hot and very humid air that had been advected over Belgium during the night (2829 June 2005), and which was characterised by high temperature and high dew point temperature at the surface (see Fig. 3). In a short period of few hours in the neighbourhood of these lines, several clusters of convective cells were developing (see hourly radar precipitation in Fig. 1). The analysis at $850 \mathrm{hPa}$ (based on the ECMWF data and on radiosonde observations over Western Europe) indicated a warm and humid air mass in the low troposphere over Belgium (see Fig. 2a). The $500 \mathrm{hPa}$ geopotential height analysis showed a diffluent air flow pattern in the mid-troposphere (see Fig. 2b). A dynamic coupling between a marked trough centred over north-western France and a complex surface depression over Belgium had reinforced the air instability. Several convective cells were observed by the SEVIRI instrument on Meteosat (infrared channel; see Fig. 6). A signature of cloud stretching (favoured by the wind shear) and vertical development along the identified convergence line (see Fig. 3) were observed by the SEVIRI composite visible image (Fig. 7). The intensification of convective activity induced a complex meso-scale convective system which covered Belgium, resulting in heavy precipitation (up to $100 \mathrm{~mm} /$ day). The use of a numerical weather prediction model (ECMWF and the regional model ALADIN), the use of synoptic data and the near real-time meteorological observations (radar, SAFIR, Meteosat) were not so helpful for the nowcasting (see Sect. 2 for more details). For this reason, we decided to develop a new approach of the use of GNSS tropospheric measurements. The time resolution of our calculations of GNSS observations (from 26 June to 2 July 2005) used in this study is 5 and $15 \mathrm{~min}$. The Belgian GNSS dense network (about 
Table 4. Statistical results (i.e. number of alerts and final scores) between 10:45 and 13:30 UTC on 29 June 2005. The time resolution of GNSS observations is $5 \mathrm{~min}$ (post-processing and operational runs). The statistical results obtained without the use of pseudo-ZTD established from gradients are presented in brackets.

\begin{tabular}{|c|c|c|c|c|c|c|c|c|}
\hline \multirow{3}{*}{$\begin{array}{c}\text { Periods } \\
\text { 29 Jun } 2005 \text { 10:45 }\end{array}$} & \multicolumn{4}{|c|}{ Reference processing } & \multicolumn{4}{|c|}{ Fast processing } \\
\hline & \multicolumn{2}{|c|}{$\mathrm{H}_{2} \mathrm{O}$ alerts } & \multicolumn{2}{|c|}{ Score } & \multicolumn{2}{|c|}{$\mathrm{H}_{2} \mathrm{O}$ alerts } & \multicolumn{2}{|c|}{ Score } \\
\hline & 0 & $(0)$ & l & $(/)$ & 0 & $(0)$ & l & $(/)$ \\
\hline 29 Jun 2005 10:50 & 0 & (0) & l & $(/)$ & 0 & $(0)$ & l & $(/)$ \\
\hline 29 Jun 2005 10:55 & 0 & (0) & l & $(/)$ & 0 & $(0)$ & l & $(/)$ \\
\hline 29 Jun 2005 11:00 & 0 & (0) & l & $(/)$ & 0 & $(0)$ & l & $(/)$ \\
\hline 29 Jun 2005 11H05 & 0 & (0) & I & $(/)$ & 0 & $(0)$ & l & $(/)$ \\
\hline 29 Jun 2005 11:10 & 0 & $(0)$ & I & $(/)$ & 0 & $(0)$ & l & $(/)$ \\
\hline 29 Jun 2005 11:15 & 32 & $(0)$ & $53.1 \%$ & $(/)$ & 0 & $(0)$ & l & $(/)$ \\
\hline 29 Jun 2005 11:20 & 15 & (0) & $66.7 \%$ & $(/)$ & 0 & (0) & l & $(/)$ \\
\hline 29 Jun 2005 11:25 & 0 & $(0)$ & I & $(/)$ & 0 & (0) & l & $(/)$ \\
\hline 29 Jun 2005 11:30 & 24 & (20) & $62.5 \%$ & $(65.0 \%)$ & 0 & $(0)$ & l & $(/)$ \\
\hline 29 Jun 2005 11:35 & 2 & $(0)$ & $50.0 \%$ & $(/)$ & 0 & $(0)$ & I & $(/)$ \\
\hline 29 Jun 2005 11:40 & 3 & $(0)$ & $0.0 \%$ & $(/)$ & 36 & $(0)$ & $30.6 \%$ & $(/)$ \\
\hline 29 Jun 2005 11:45 & 63 & (85) & $62.0 \%$ & $(36.5 \%)$ & 132 & (14) & $37.9 \%$ & $(7.1 \%)$ \\
\hline 29 Jun 2005 11:50 & 23 & (20) & $26.1 \%$ & $(40.0 \%)$ & 0 & $(0)$ & I & $(/)$ \\
\hline 29 Jun 2005 11:55 & 0 & $(0)$ & I & $(/)$ & 0 & $(0)$ & I & $(/)$ \\
\hline 29 Jun 2005 12:00 & 6 & (0) & $100.0 \%$ & $(/)$ & 12 & $(0)$ & $66.7 \%$ & $(/)$ \\
\hline 29 Jun 2005 12:05 & 0 & (0) & I & $(/)$ & 0 & (0) & I & $(/)$ \\
\hline 29 Jun 2005 12:10 & 8 & (0) & $100.0 \%$ & $(/)$ & 0 & (0) & l & $(/)$ \\
\hline 29 Jun 2005 12:15 & 21 & (0) & $85.7 \%$ & $(/)$ & 0 & (0) & l & $(/)$ \\
\hline 29 Jun 2005 12:20 & 4 & (0) & $100.0 \%$ & $(/)$ & 0 & (0) & I & $(/)$ \\
\hline 29 Jun 2005 12:25 & 23 & (1) & $87.0 \%$ & $(100.0 \%)$ & 23 & (9) & $78.3 \%$ & $(44.4 \%)$ \\
\hline 29 Jun 2005 12:30 & 181 & (123) & $50.3 \%$ & $(52.8 \%)$ & 227 & (192) & $44.1 \%$ & $(38.4 \%)$ \\
\hline 29 Jun 2005 12:35 & 41 & $(32)$ & $100.0 \%$ & $(100.0 \%)$ & 38 & (19) & $100.0 \%$ & $(100.0 \%)$ \\
\hline 29 Jun 2005 12:40 & 13 & $(0)$ & $100.0 \%$ & (/) & 7 & $(0)$ & $100.0 \%$ & (/) \\
\hline 29 Jun 2005 12:45 & 80 & (46) & $91.3 \%$ & $(89.1 \%)$ & 94 & (24) & $90.4 \%$ & $(100.0 \%)$ \\
\hline 29 Jun 2005 12:50 & 44 & $(7)$ & $100.0 \%$ & $(100.0 \%)$ & 22 & (1) & $95.5 \%$ & $(100.0 \%)$ \\
\hline 29 Jun 2005 12:55 & 28 & $(8)$ & $42.9 \%$ & $(12.5 \%)$ & 9 & $(0)$ & $0.0 \%$ & (/) \\
\hline 29 Jun 2005 13:00 & 115 & (59) & $95.7 \%$ & $(100.0 \%)$ & 40 & (13) & $100.0 \%$ & $(100.0 \%)$ \\
\hline 29 Jun 2005 13:05 & 27 & $(5)$ & $100.0 \%$ & $(100.0 \%)$ & 0 & $(0)$ & I & (/) \\
\hline 29 Jun 2005 13:10 & 13 & $(0)$ & $100.0 \%$ & $(/)$ & 0 & $(0)$ & I & $(/)$ \\
\hline 29 Jun 2005 13:15 & 167 & (159) & $76.6 \%$ & $(74.8 \%)$ & 140 & (158) & $98.6 \%$ & $(97.5 \%)$ \\
\hline 29 Jun 2005 13:20 & 69 & $(37)$ & $100.0 \%$ & $(100.0 \%)$ & 10 & $(0)$ & $100.0 \%$ & (/) \\
\hline 29 Jun 2005 13:25 & 1 & $(0)$ & $100.0 \%$ & (/) & 10 & (0) & $100.0 \%$ & $(/)$ \\
\hline 29 Jun 2005 13:30 & 0 & (0) & I & $(/)$ & 6 & (0) & $100.0 \%$ & $(/)$ \\
\hline all this period & 1003 & $(602)$ & $76.4 \%$ & $(69.6 \%)$ & 806 & $(430)$ & $66.5 \%$ & $(67.4 \%)$ \\
\hline
\end{tabular}

70 stations) has baselines from 5 to $30 \mathrm{~km}$ (see Fig. 8). The strategy used to measure our GNSS observations is presented in Sect. 3.

Previous work by Walpersdorf et al. (2001) showed the use of GNSS to describe the approach of a front towards Marseille in the south-east of France in 1998. Iwabuchi et al. (2003) also showed that the temporal and spatial variations of GNSS gradients matched well with the moisture field determined by ZTD and with the meteorological condition in summer 1996 over the Japan Islands (in particular during the passage of a weather front). In our study we validate the application of GNSS for meteorology by comparison with synoptic observations, weather radar and SEVIRI instrument on Meteosat satellite. We have shown that GNSS gradients with high amplitudes point in the direction of tropospheric wet structures identified by radar and SEVIRI (correspondence of $65 \%$ between high values of each techniques; see Sect. 5). This paper shows how the use of GNSS gradients can improve the resolution of the ZTD field and the estimation of water vapour (see Sect. 3.3). Note that GNSS delay variations are driven by integrated water vapour (IWV) content variations. In this study we prefer to use initial GNSS ZTD measurements rather than IWV conversion (Brenot et al., 2006). A meticulous observation of ZTD and gradient 

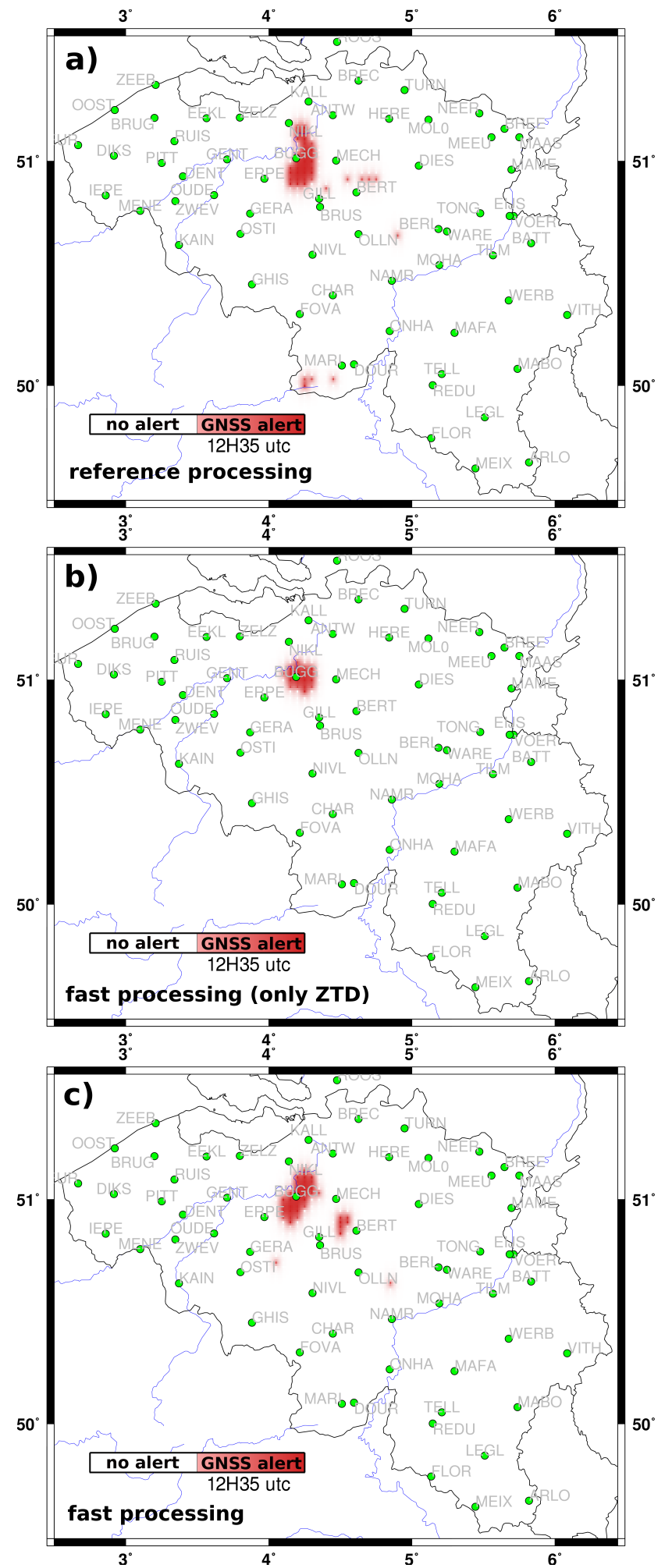

Figure 17. 2-D fields of GNSS $\mathrm{H}_{2} \mathrm{O}$ alerts ( 0 or 1$)$ on 29 June 2005 at 12:35 UTC: (a) from reference post-processing measurements (with ZTD and gradients), (b) from fast measurements (ZTD only), and (c) from fast measurements (with ZTD and gradients). time series has shown that a typical configuration of the water vapour field can be observed before the initiation of deep convection. A dry/wet contrast in time (strong increase and decrease) and in space (dry/wet dipole formed by two regions a few kilometres distant) can take place a few tens of minutes beforehand. This dry/wet contrast of GNSS ZTD field allows for us to establish $\mathrm{H}_{2} \mathrm{O}$ alerts based on a substantial decrease of ZTD (at least $8 \mathrm{~mm}$ ) followed by a strong increase of ZTD (at least $15 \mathrm{~mm}$ ) over two time periods each of $15 \mathrm{~min}$ (the total process lasts $30 \mathrm{~min}$ ), as shown in Sect. 4. To validate our GNSS alert, we present two external meteorological indicators of deep convection (see Sect. 5). The first one uses C-band weather radar $(5.64 \mathrm{GHz}$ frequency) and echoes top measurements (reflectivities larger or equal to $38 \mathrm{dBZ}$ at an altitude higher than $5 \mathrm{~km}$ ), which represents a good indicator. The second one uses infrared radiance from the SEVIRI instrument on Meteosat Second Generation. If effective IR radiance (channel 09) is less than 200 DC, which corresponds to a cloud top temperature of about $232.75 \mathrm{~K}$ for this channel, we consider that deep convection has taken place. To estimate the score of our $\mathrm{H}_{2} \mathrm{O}$ alert by GNSS we consider that an alert is validated if an indicator of deep convection (by radar and/or by SEVIRI) takes place $50 \mathrm{~min}$ after this alert. Alerts and indicators are established for the same grid (pixel $3 \mathrm{~km} \times 3.5 \mathrm{~km}$ ). Using post-processed observations, the score obtained is more than $80 \%$ for the week of our case study (see Sect. 6.1). Note that final and ultra-rapid IGS orbits have been tested and show equivalent results. We show in Table 3 that an increase of ZTD and gradient time resolution (linear interpolation) can improve our GNSS alert system. In fact, the number of alerts increased and in some cases, alerts took place earlier. Then the next step of the validation of our method to generate $\mathrm{H}_{2} \mathrm{O}$ alerts is to use fast measurements (equivalent to near real-time observations obtain in less than 10 min of calculations). Fast ZTD and gradients were processed for 29 June 2005 with a time resolution of $5 \mathrm{~min}$. We found a very good agreement between reference and fast post-processed measurements (less than $10 \mathrm{~mm}$ for the ZTD and less than $3 \mathrm{~mm}$ for the gradient components; see Fig. 16). The localisation of alerts generated by reference and fast post-processed observations are in good agreement (as shown in Fig. 17a and c). The advantage of using the gradients to improve the spatial resolution and the number of GNSS $\mathrm{H}_{2} \mathrm{O}$ alerts is presented in Table 4 and Fig. 17b and c). The score obtained for the $\mathrm{H}_{2} \mathrm{O}$ alerts generated by fast observations is $65 \%$, which confirms our method.

Strong amplitudes of horizontal gradients point to wet areas with strong instability. These measurements represent a real opportunity for nowcasting. We have shown the key role of GNSS ZTD combined with horizontal gradients in detecting water vapour blobs and convergences (time and space contrasts between wet and dry regions), which are precursors of deep convection. The rainfall event of 2005 is an unusual situation with the creation of a significant number of 


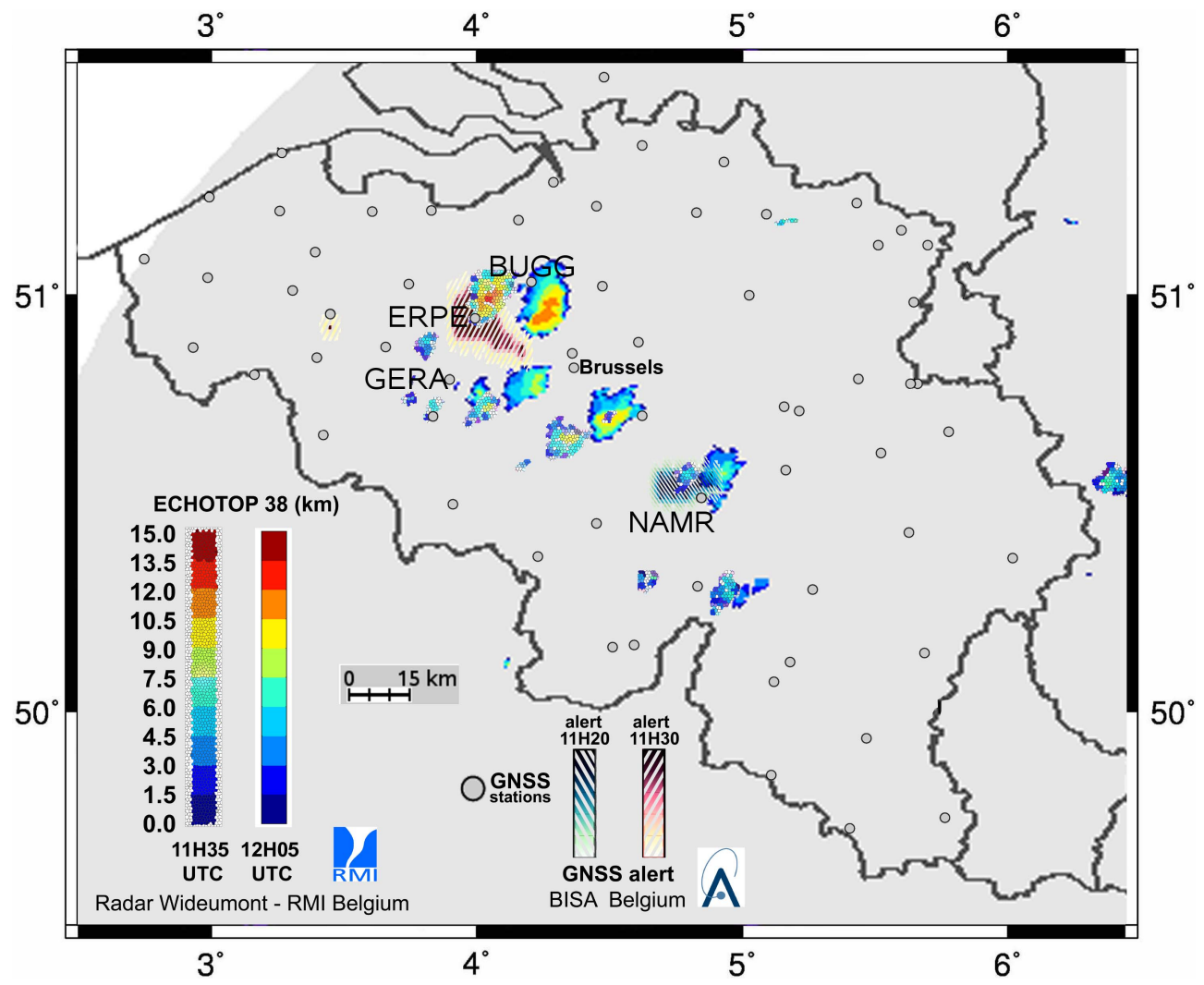

Figure 18. GNSS H2O alerts (11:20 and 11:30 UTC) and radar echoes top (altitude of the highest $38 \mathrm{dBZ}$ radar echo) at 11:35 and 12:05 UTC, on 29 June 2005.

convective cells. We plan to test our method for other weather situations.

In this study, our reference for ZTD and gradients observations was calculated with final satellites orbits using precise positions and a sliding windows strategy (see Sects. 3.1 and 3.2). These observations have a high sensitivity to the small variations of the water vapour field. The estimation of operational ZTD and gradients is not optimal due to the fast calculations and the impossibility to use the sliding windows strategy in near real-time (NRT). However, our first result of validation of our method is a good motivation to test it with NRT ZTD (and gradient if available) measurements, like within the framework of EUMETNET GPS Water Vapour (EGVAP project, 2004-2008, 2009-2012; see Haan et al., 2006). Clearly the score cannot be as good as with post-processed observations. The use of improved mapping functions (Boehm and Schuh, 2004; Boehm et al., 2006a, b) and the increase of positioning solutions (Tregoning and Watson, 2009, 2011) show that the quality of NRT ZTD measurements is increasing as well as the time delay (about 5 min after the observation times) to obtain NRT observations (Haan et al., 2009). Nevertheless, NRT gradients clearly need to be considered to increase the number of alerts generate by our method.
It is important to combine good quality ZTD and gradient observations (highly sensitive to quick variations of the local water vapour field) with a time delay less than $10 \mathrm{~min}$ after observation time (for an operational use). We are considering using such a GNSS alert system in Belgium to support forecasters, as shown in Fig. 18. A quality check procedure of our observations needs to be established. The quality of measurements depends on the precision of the positions of stations and on the number and the spatial distribution of these stations. On the other hand, the time of calculations increases non-linearly with the number of stations. A good balance between the time of calculations and the quality of measurements is required to generate NRT GNSS $\mathrm{H}_{2} 0$ alerts. In addition to a good ratio of quality/time delivery of observations, improvement of such a service in NRT could also come from the combination of our $\mathrm{H}_{2} \mathrm{O}$ alert strategy with numerical weather prediction. More precise forecasts of locations of deep convection initiation could be expected with such an approach.

Acknowledgements. We would like to thank WALCORS, FLEPOS, EUREF, IGS, and René Warnant for providing the rinex data used in this paper. Thank you also to Bob King for the use of GAMIT software and to Paul Wessel for all the useful Generic Mapping Tools (GMT). We thank also Fabian Debal, David Delbecq and 
Luc Gérard for their support, advice and help in the final achievement of this study. We really appreciate and are grateful for all the support, comments and corrections that Geraint Vaughan, editor of this special issue of the Water Vapour in the Climate System (WAVACS) COST action, gave to us. The authors gratefully thank Dave Adams for his review and his relevant comments, which have really contributed to the improvement of this manuscript.

Edited by: G. Vaughan

\section{References}

Altamimi, Z., Sillard, P., and Boucher, C.: ITRF 2000: A New Release of the International Terrestrial Reference Frame for Earth Science Applications, J. Geophys. Res., 107, 2214, doi:10.1029/2001JB000561, 2002.

Bar-Sever, Y. E. and Kroger, P. M.: Estimating Horizontal Gradients of Tropospheric Path Delay with a Single GPS Receiver, J. Geophys. Res., 103, 5019-5035, 1998.

Bevis, M., Businger, S., Herring, T. A., Rocken, C., Anthes, R. A., and Ware, R. H.: GPS Meteorology : Remote Sensing of Atmospheric Water Vapor Using the Global Positioning System, J. Geophys. Res., 97, 15787-15801, doi:10.1029/92JD01517, 1992.

Bock, Y. R., Abbot, R. I., III, C. C. C., Gourevitch, S. A., and King, R. W.: Establishment of Three-Dimentional Geodetic Control via Interferometry with Global Positioning System, J. Geophys. Res., 90, 7689-7703, doi:10.1029/JB090iB09p07689, 1985.

Bock, Y. R., Gourevitch, S. A., III, C. C. C., King, R. W., and Abbot, R. I.: Interferometric Analysis of GPS Phase Observations, Manuscr. Geodaet., 11, 282-288, 1986.

Boehm, J. and Schuh, H.: Vienna mapping functions in VLBI analyses., Geophys. Res. Lett., 31, L01603, doi:10.1029/2003GL018984, 2004.

Boehm, J., Niell, A. E., Tregoning, P., and Schuh, H.: Global Mapping Function (GMF): A new empirical mapping function based on numerical weather model data., Geophys. Res. Lett., 33, L07304, doi:10.1029/2005GL025546, 2006 a.

Boehm, J., Werl, B., and Schuh, H.: Troposphere mapping functions for GPS and very long baseline interferometry from European Centre for Medium-Range Weather Forecasts operational analysis data., J. Geophys. Res., 111, B02406, doi:10.1029/2005JB003629, 2006b.

Brenot, H.: Potentiel de la mesure GPS sol pour l"étude des pluies intenses méditerranéennes., Ph.D. thesis, Université Joseph Fourier de Grenoble, 2006 (in French and English).

Brenot, H. and Warnant, R.: Characterization of the tropospheric small-scale activity, Technical Report ESA, WP250, GALOCAD project, 2008.

Brenot, H., Ducrocq, V., Walpersdorf, A., Champollion, C., and Caumont, O.: GPS zenith delay sensitivity evaluated from highresolution numerical weather prediction simulations of the 8-9 September 2002 flash flood over southeastern France, J. Geophys. Res., 111, D15105, doi:10.1029/2004JD005726, 2006.

Brunner, F. and Gu, M.: An Improved Model for the Dual Frequency Ionospheric Correction of GPS Observations, Manuscr. Geodaet., 16, 205-214, 1991.

Chen, G. and Herring, T. A.: Effects of Atmospheric Azimuthal Asymetry on the Analysis of Space Geodetic Data, Geophys.
Res. Lett., 102, 20489-20502, doi:10.1029/97JB01739, 1997.

Davis, J. L., Elgered, G., Niell, A. E., and Kuehn, C. E.: Groundbased Measurements of Gradients in the "Wet" Radio Refractivity of air, Radio Science, 28, 1003-1018, doi:10.1029/93RS01917, 1993.

Delobbe, L. and Holleman, I.: Uncertainties in radar echo top heights used for hail detection, Meteor. Appl. (Royal Met. Society), 13, 361-374, 2006.

Dong, D.-N. and Bock, Y.: Global Positioning System Network Analysis With Phase Ambiguity Resolution Applied to Crustal Deformation Studies in California, J. Geophys. Res., 94, 39493966, 1989.

Gradinarsky, L. P.: Sensing Atmospheric Water Vapor Using Radio Waves, Ph.D. thesis, School of Electrical Engineering, CHALMERS University of Technology, Gothenburg, Sweden, 2002.

Haan, S., Jones, J., and Vedel, H.: EUMETNET GPS Water Vapour (EGVAP), Presentation at European Meteorological Society, Ljubljana, Slovenia, 2006.

Haan, S., Holleman, I., and Holtslag, A. A. M.: Real-Time Water Vapor Maps from a GPS Surface Network: Construction, Validation, and Applications, J. Appl. Meteor., 45, 467-475, doi:10.1175/JAM2338.1, 2009.

Herring, T. A., Davis, J. L., and Shapiro, I. I.: Geodesy by Radio Interferometry: The Application of Kalman Filtering to the Analysis of Very Long Baseline Interferometry Data, J. Geophys. Res., 95, 12561-12581, doi:10.1029/JB095iB08p12561, 1990.

Herring, T. A., King, R. W., and McClusky, S. C.: Documentation for the GAMIT GPS Analysis Software, version 10.4, Tech. rep., Mass. Inst. Tech., Cambridge, USA, 2010.

Iwabuchi, T., Miyazaki, S., Heki, K., Naito, I., and Hatanaka, Y.: An impact of estimating tropospheric delay gradients on tropospheric delay estimations in the summer using the Japanese nationwide GPS array, J. Geophys. Res., 108, 4315, doi:10.1029/2002JD002214, 2003.

King, R. W., Masters, E. G., Rizos, C., Stolz, A., and Collins, J.: Surveying with GPS, Monograph 9, School of Surveying, University of New South Wales, Kensington, Australia, 1985.

Leick, A.: GPS Satellite Surveying, WILEY-INTERSCIENCE, 1989.

Neméghaire, J. and Brenot, H.: Etude du potentiel d'utilisation des observations GNSS pour l'analyse météorologique et la prévision à très court terme, Publication scientifique de l'Institut Royal Météorologique de Belgique, available at: http://h2o.oma. be/RMIB_num59_oct2010.pdf, October 2010 (in French).

Niell, A.: Global Mapping Functions for the Atmosphere Delay at Radio Wavelengths, J. Geophys. Res., 101, 3227-3246, 1996.

Saastamoinen, J.: Atmospheric Correction for the Troposphere and Stratosphere in Radio ranging of satellites, Geophys. Monogr. Ser., 15, 247-251, doi:10.1029/GM015p0247, edited by: Henriksen, S. W., Mancini, A., and Chovitz, B. H., 1972.

Smith, W. H. F. and Wessel, P.: Gridding with continuous curvature splines in tension, Geophysics, 55, 293-305, doi:10.1190/1.1442837, 1990.

Spilker, J. J.: Global Positioning System, Vol I., The Institute of Navigation, 1980.

Tregoning, P., Boers, R., O'Brien, D., and Hendy, M.: Accuracy of Absolute Precipitable Water Vapor Estimates from GPS Observations, J. Geophys. Res., 103, 28701-28710, 
doi:10.1029/98JD02516, 1998.

Tregoning, P. and Herring, T. A.: Impact of a priori zenith hydrostatic delay errors on GPS estimates of station heights and zenith total delays, Geophys. Res. Lett., 33, L23303, doi:10.1029/2006GL027706, 2006.

Tregoning, P. and Watson, C.: Atmospheric effects and spurious signals in GPS analyses, J. Geophys. Res., 114, B09403, doi:10.1029/2009JB006344, 2009.

Tregoning, P. and Watson, C.: Correction to "Atmospheric effects and spurious signals in GPS analyses", J. Geophys. Res., 116, B02412, doi:10.1029/2010JB008157, 2011.
Vedel, H., Mogensen, K., and Huang, X.-Y.: Calculation of Zenith Delays From Meteorological Data Comparison of NWP Model, Radiosonde and GPS Delays, Phys. Chem. Earth, 26, 497-502, 2001.

Walpersdorf, A., Calais, E., Haase, J., Eymard, L., Desbois, M., and Vedel, H.: Atmospheric Gradients Estimated by GPS Compared to a High Resolution Numerical Weather Prediction (NWP) Model, Phys. Chem. Earth, 147-152, 2001. 